\title{
Assessment of Drought Event, its Trend and Teleconnected Factors Over Burundi, Central East Africa
}

\section{Athanase Nkunzimana ( $\sim$ athanase.nkunzimana@yahoo.fr )}

Nanjing University of Information Science and Technology https://orcid.org/0000-0003-1675-1522

\section{Bi Shuoben}

Nanjing University of Information Science and Technology

\section{Wang Guojie}

Nanjing University of Information Science and Technology

Ahmed Alriah Mohamed Abdallah

Nanjing University of Information Science and Technology

Isaac Sarfo

Nanjing University of Information Science and Technology

Xu Zhihui

Nanjing University of Information Science and Technology

Floribert Vuguziga

Nanjing University of Information Science and Technology

Brian Ayugi Odhiambo

Nanjing University of Information Science and Technology

\section{Research Article}

Keywords: SPI index, drought severity, drought intensity, abrupt point, atmospheric factors

Posted Date: March 10th, 2021

DOI: https://doi.org/10.21203/rs.3.rs-259551/v1

License: (c) (1) This work is licensed under a Creative Commons Attribution 4.0 International License. Read Full License 


\title{
Assessment of drought event, its trend and teleconnected factors over Burundi, Central East Africa
}

Athanase Nkunzimana ${ }^{1,2, *}$, Bi Shuoben ${ }^{1,}$ Wang Guojie ${ }^{1}$, Mohamed Abdallah Ahmed Alriah ${ }^{1}$, Isaac $\mathrm{Sarfo}^{3}$, Xu Zhihui ${ }^{3}$, Floribert Vuguziga ${ }^{4}$, Brian Odhiambo Ayugi ${ }^{4}$

${ }^{1}$ School of Geographical Sciences, Nanjing University of Information Science and Technology, Nanjing 210044, China

${ }^{2}$ Department of Geography, University of Burundi, P.O. Box 5142, Bujumbura, Burundi

${ }^{3}$ Research Institute for History of Science \& Technology, Nanjing University of Information Science \& Technology, Nanjing 210044, China

${ }^{4}$ Collaborative Innovation Center on Forecast and Evaluation of Meteorological

Disasters/Key Laboratory of Meteorological Disaster, Ministry of Education, Nanjing

University of Information Science and Technology, Nanjing 210044, China

*Corresponding author: Athanase Nkunzimana

\begin{abstract}
This study assessed the drought events across Burundi for 37 years ranging from 1981 to 2017. The drought assessment was conducted using the Standardized Precipitation Index (SPI) at 1, 3, 6 and 12-month time scales. The Mann Kendall and Modified Mann Kendall trend tests and Sen's slope statistic tests were used to analyse the spatiotemporal drought trend. The overall analysis of SPI-3, SPI-6 and SPI-12 outputs revealed that the Northern part of Burundi was the most threatened by dry events, and more than $80 \%$ of the extremely and severely dry events occurred within the period 1993-2000. The drought magnitude varied highly in the short rains season (SOND) than during the long rains season (MAM) specifically during the 1990s decade. The cumulative frequency of extremely dry events was very high in the North with $5.2 \%, 6.1 \%$ and $7.4 \%$ at 3,6 and 12-month time scales respectively. Likewise, the northern part experienced both short, medium and long dry periods, thus 88 consecutive dry months within only 8 years. The North and East regions exhibited a positive increasing trend over annual and seasonal time scales at both 3, 6, and 12 months of SPI analysis while the mountainous region and the South experienced a significant decreasing trend. The first abrupt point issued by forward and backward sequential statistics occurred in 1990, the year corresponding to the beginning of the driest period. Dry years are associated with circulation anomalies over the Indian Ocean and La Nina events.
\end{abstract}

Keywords: SPI index, drought severity, drought intensity, abrupt point, atmospheric factors 


\section{Introduction}

The drought is among the most common climate extreme events affecting several regions of the world, especially in the African continent. It is known to be the most destructive disaster that affects directly or indirectly the ecosystems and socioeconomic activities (Ionita et al. 2016). The drought leads to land degradation and desertification causing crop failure, food shortages, famine, malnutrition, deaths and mass migration (Winkler et al. 2017). It is among the factors that increase the rate of hunger and poverty over different regions specifically in Africa ( Otto et al. 2015; Gebrechorkos et al. 2018). Various factors are attributed to the occurrence and intensity of drought events. Recent studies showed that recurrent drought events result from climate variability resulting in the shift of intensity and the frequency of the precipitation at regional and local scales (Wu et al. 2016). Therefore, drought frequency, duration and intensity are varying from one region to another and induced losses differ depending on the drought duration and intensity (Onyutha and Willems 2017a).

Africa has been threatened by drought hazards for so long (Mwangi et al. 2014; Gebremeskel et al. 2019). It shall be recalled that more than $85 \%$ of the African population relies on rainfed agriculture. However, the recurrent drought hazards cause crop failure that leads to food shortages and humanitarian crises in general (Ou and Hao 2018). The Greater Horn of Africa (GHA) is among the most threatened by drought events(Lyon 2014; Nicholson, 2014; Mpelasoka et al. 2018; Gebremeskel Haile et al. 2020). According to the World Health Organization, the Greater Horn of Africa region registers many deaths due to drought hazards, and the most affected countries are Somalia, Ethiopia and Kenya (Bayissa et al. 2017; Zeleke et al. 2017; Abro et al. 2019; Gebremeskel et al. 2019; Nguvava et al. 2019; Polong et al. 2019; Ayugi et al. 2020). Gebremeskel et al. (2019) established that apart from the great horn of Africa, the drought is extending toward other countries of the East and Central East Africa. However, there is a lack of drought studies over most of the countries of Central East Africa. Therefore, it is important to investigate drought events over a national scale for agriculture and economic sustainability.

Like most countries of Central East Africa, Burundi is facing recurrent drought events resulting in human and socio-economic activities losses. The North and East parts of Burundi have been affected by recurrent drought events for decades. The recent severe droughts started in 1993 and became recurrent in 2000, 2003, 2005, 2007 and 2010. More than 100000 people are victim of drought hazards every year in Burundi (FSNWG, 2010). In 2010, about 178550 people needed humanitarian emergency assistance in the northern part of Burundi. Apart from the two regions, the hydric deficit affects the socio-economic activity of the whole country. Most of the hydropower centers went off due to the lack of water into the dams during the past drought occurrence. The typical example is the 2007 drought event that seriously affected the hydropower station of Rwegura leading to severe economic decline especially in the capital city of Bujumbura and most of the centers alimented by that hydropower station. The same situation was reported at the hydropower stations of Kavuruga in Muyinga and Nyemanga in East of Burundi.

From 2010, Burundi tried to establish a number of methods to mitigate drought and flood hazards. However, it is not easy to assess drought events and its impact on economy that mainly relies on rain-fed agriculture. The report on validation of the disaster risk reduction strategy over Burundi carried out that more than $90 \%$ of Burundian live on agriculture with a contribution of more than 44\% of the Gross Domestic Product (GDP) providing 95\% of exportation income (MEEATU\&MINAGRIE 2014). 
Therefore, any drought event directly affects not only the local population but also the whole economy of Burundi. In 2015, more than 42000 persons were estimated as victim of extreme weather events in Burundi. About 1 million of Burundian people were under famine risk which is attributed to the direct impact of drought events.

Many factors combine to explain the causes of droughts. It is necessary to understand the rainfall mechanism in order to assess the drought events over a given region. Ngarukiyimana et al. (2017a) found out that the dry and wet conditions observed over Central East Africa especially over Rwanda and Burundi have originated from the Atlantic Ocean on one hand and from the Indian Ocean on the other hand. The same conclusion was found by several authors who studied climate variability over East Africa (Hastenrath, 2007; Ogwang et al. 2015; Philippon et al. 2015; Ongoma et al. 2015; Ayugi et al. 2018; Cattani et al. 2018). Some scientists have investigated the relationship between atmospheric drivers such as El Nino Southern Oscillation (ENSO), Indian Ocean Dipole (IOD), subtropical high, etc. (Shanko and Camberlin 1998; Nicholson 2015; Ogwang et al. 2015a; Shan et al. 2018; Forootan et al. 2019). Black (2005) found that the wet conditions are associated with warming in the Pacific and West of Indian Oceans while dry events are mostly linked to cooling in the Eastern Indian Ocean. Nicholson and Kim (1997);(Camberlin et al. 2001); (Mutai and Ward 2000) discovered a close correlation between SST anomalies caused by ENSO in the Indian Ocean and interannual rainfall fluctuations across East Africa. They indicated that ENSO is extensively associated with climate patterns in the Indian Ocean, monsoon seasons, and circulation Eastern-Western over Equator circulation.

The drought events assessment has become a preoccupation of both the Scholars and policymakers. Several studies on drought monitoring, evaluation and trend analysis have been conducted worldwide to establish a forecasting system to overcome or reduce losses in case of occurrence. Therefore, different methods are used to assess and analyse the drought frequency, severity and intensity. Some of the commonly used techniques are the Standardized Precipitation Index (SPI), Standardized Precipitation Evaporation Index (SPEI), percentile precipitation, among others. These methods have been widely employed in drought events assessment. For instance, Pramudya et al. 2019 used the SPI method to evaluate the drought conditions over Australia to identify the most threatened zones lying under severe drought and areas of high susceptibility across the country. The SPI has been the choice of more scholars in monitoring and analysing drought disasters over different regions in China (Ali et al. 2020; Ayuso et al. 2015; He et al. 2015; Li et al. 2013; Liu et al. 2009; Musonda et al. 2020 ; Mohammed et al. 2020; Hesam et al 2021). Due to the complexity of the drought disaster, some scientists prefer to use the SPEI that combines both precipitation and evapotranspiration to monitor and evaluate the drought hazard over spatial and temporal scales (Haile et al. 2020; wang et al. 2020; Qaiser et al. 2021). For instance, Shi et al. (2017) utilised SPEI to study the drought over Henan province for 53 years ranging from 1961 to 2013. They succeeded to evaluate the drought intensity over decadal, seasonal, annual and long-term scales over different regions using SPEI. It was found to deliver a consistent result for both temporal and spatial scales. Likewise, several studies have used SPEI to assess drought events in different regions (Benlin et al. 2017; Ahmed et al. 2018; Polong et al. 2019; Uddin et al. 2020; Zhai et al. 2020)

Although SPI is among methods recommended by the World Meteorological Organization to monitor drought events (Svoboda and Fuchs 2017a), only a few studies were conducted over Africa, specifically over the Central East Africa region. Most of the studies conducted over Africa revealed that the SPI method can provide consistent results. e.g. 
Elkollaly et al (2018) used SPI to assess drought events over the East of the Nile river basin and revealed that many drought events occurred during both the long rains and the short rains seasons. Okpara et al. (2017) also tested the applicability of SPI by analysing the drought features for an early warning system over West Africa. Similar work was conducted over the North of Africa in Morocco and Tunisia (Jemai et al. 2018; Zhim et al. 2019). Gebremeskel et al. (2020) analysed the long-term drought variability over the Greater Horn of Africa using SPEI and revealed that Somalia, Ethiopia and Kenya experienced more severe drought. In the southwest part of Africa, Byakatonda et al. (2018) used SPI and SPEI methods to study the semi-arid drought severity over Botswana and found that drought areas with $96 \%$ of confidence at 12 monthly timescales. The Mann-Kendall Z-statistic and Sen's slope estimator were employed to analyze the monotonic changes of the drought (Byakatonda et al. 2018).

Though the SPI method allows the assessment and analysis of the drought events, it is important to analyse the drought trend over time. For that purpose, several researchers used Sen's slope estimator and Mann-Kendall's trend to determine the magnitude and statistical significance of the rainfall( Mahajan and Dodamani 2015; Lopes et al. 2016; Tosunoglu and Kisi 2017; Guo et al. 2018). In order to avoid the risk of accepting false significance induced by the existence of positive or negative autocorrelation, some scholars prefer to use the Modified Mann Kendall method(Nashwan et al. 2019; Sa'adi et al. 2019).

This study aimed at investigating the drought occurrence, its frequency, intensity, and duration over Burundi for a period of 37 years ranging from 1981 to 2017 using the standardized precipitation index (SPI) method. It allowed identifying the areas that experienced more dry events or less dry events. Regions of positive or negative trends were depicted allowing to determine regions under drought risk. This will help policymakers to implement new policies about drought early warning and crop growing season regulation.

The remaining sections are structured as follows: the Section 2 concerns the study area and datasets, Section 3 introduces the methodology, Section 4 presents the results and discussions and finally comes the conclusion in Section 5.

\section{Study area and datasets}

\subsection{Study area}

Burundi is a landlocked country located at the southernmost part of the Nile River basin, straddled East and central Africa, bordering Rwanda to the North, Tanzania to the East and the Democratic Republic of Congo (DRC) to the West. It is bounded within latitude $2^{\circ} 15^{\prime}$ $4^{\circ} 30 \mathrm{~S}$ and longitude $28^{\circ} 58^{\prime}-30^{\circ} 53^{\prime} \mathrm{E}$ (Fig. 1). It is situated in the Great Lakes region of Africa with Lake Tanganyika to the western part that lies in the western Rift Valley of Africa. It is characterised by five different topographical unities representing five micro-climate zones. From West to East, the study domain is dominated by plains, Escarpments of Mirwa, Congo-Nile ridge, plateau and depressions.

The location in the equatorial band enables the study domain to benefit a tropical climate. It is characterised by a bimodal rainfall regime corresponding to the movement of the Intertropical Convergence Zone (ITCZ). Like most of the Central East Africa, Burundi generally experiencies two wet seasons namely MAM (March-April-May) known as long rains season and SOND (September-October-November-December) usually regarded as short 
rains seasons ( Philippon et al. 2015; Ongoma et al. 2016a; Ayugi et al. 2018; Nkunzimana et al. 2020a). The long rains season normally follows the ITCZ migration towards the northern hemisphere while the short rains season results from the backward movement of the ITCZ from Nord southward (Mutai et al. 1998; Ang'u et al. 2016).

The climate varies according to the topography. Thus, the western part is known as a semidry region with an annual rainfall of less than $1000 \mathrm{~mm}$ (Baramburiye et al. 2013; Nkunzimana et al. 2019b). The Escarpments of Mirwa benefits annual precipitation ranging between $1000 \mathrm{~mm}$ and $1400 \mathrm{~mm}$. The Congo-Nile Ridge zone experiences precipitation that vary from 1400 to $1600 \mathrm{~mm}$. This region can easily register more than $1600 \mathrm{~mm}$ of annual precipitation during wet years (Table 1). The central part of Burundi is mainly dominated by a plateau that registers annual precipitation varying between $1200 \mathrm{~mm}$ and $1400 \mathrm{~mm}$. The depression of North and East are characterized as semi-dry areas and record annual rainfall of less than $1000 \mathrm{~mm}$ (MINATTE 2007).

Fig. 1. Map of Africa with CEA in the red box (left), the topographical elevation of Burundi with meteorological stations and delimitation of different microclimate zones (right)

Table 1 Synoptic stations used in the study with geographical and climatological details

\begin{tabular}{|l|r|r|r|r|r|r|r|r|r|}
\hline Station & Lon & Lat & \multicolumn{1}{|c|}{$\begin{array}{c}\text { Altitud } \\
\mathrm{e}(\mathrm{m})\end{array}$} & $\begin{array}{c}\text { Annual Mean } \\
(\mathrm{mm})\end{array}$ & $\begin{array}{l}\text { Monthly } \\
\text { Mean } \\
(\mathrm{mm})\end{array}$ & Std & \multicolumn{1}{l}{$\begin{array}{l}\text { Cv } \\
(\%)\end{array}$} & $\begin{array}{l}\text { MAM } \\
(\mathrm{mm})\end{array}$ & $\begin{array}{l}\text { SOND } \\
(\mathrm{mm})\end{array}$ \\
\hline Bujumbura & 29.31 & -3.31 & 783 & 773.7 & 64.37 & 54.63 & 84.87 & 257.5 & 300.5 \\
\hline Gitega & 29.91 & -3.41 & 1645 & 1162.9 & 95.94 & 79.23 & 82.58 & 378.9 & 449.2 \\
\hline Cankuzo & 30.54 & -3.21 & 1652 & 1184.8 & 98.02 & 80.23 & 81.86 & 385.3 & 482.8 \\
\hline Gisozi & 29.68 & -3.56 & 2097 & 1514.8 & 125.5 & 95.05 & 75.73 & 506 & 592 \\
\hline Muyinga & 30.35 & -2.85 & 1756 & 1103.2 & 91.31 & 73.23 & 80.2 & 406 & 435.7 \\
\hline Musasa & 30.1 & -4 & 1260 & 1129.5 & 93.71 & 79.69 & 85.04 & 401.4 & 409 \\
\hline Nyanza-lac & 29.61 & -4.31 & 820 & 1189.6 & 98.81 & 84.77 & 85.79 & 426.2 & 467.3 \\
\hline Kirundo & 30.11 & -2.58 & 1449 & 1078.4 & 89.24 & 66.22 & 74.2 & 396.2 & 402.2 \\
\hline Kinyinya & 30.33 & -3.65 & 1308 & 1134.5 & 94.14 & 86.76 & 92.17 & 424.5 & 415 \\
\hline Tora & 29.53 & -3.73 & & 1528.3 & 127 & 93.46 & 73.6 & 524.6 & 588.3 \\
\hline Rwegura & 29.51 & -2.91 & 2302 & 1642.1 & 135.8 & 94.62 & 69.65 & 561.5 & 661.2 \\
\hline Bugarama & 29.55 & -3.3 & 2240 & 1570.3 & 130.1 & 95.95 & 73.73 & 542.4 & 620.8 \\
\hline Makamba & 29.81 & -4.13 & 1450 & 1234.5 & 102.4 & 85.01 & 82.98 & 440.5 & 487.6 \\
\hline Nyamuswaga & 30.03 & -2.88 & 1720 & 1251 & 103.7 & 83.7 & 80.7 & 453.6 & 503.1 \\
\hline Mparambo & 29.08 & -2.83 & 887 & 959.5 & 79.53 & 55.03 & 69.19 & 352.6 & 346 \\
\hline
\end{tabular}

\subsection{Datasets}

This study utilised ground observation data sourced from Burundi Geographical Institute (IGEBU). Fifteen stations distributed across Burundi were collected to assess the drought intensity, frequency and duration. Selected stations have recorded data ranging from 1981 to 2017. The dataset was first of all checked and controlled before use. 
Missing data were filled using linear mean and cross mean interpolation. It is worth mentioning that the stations with historical data of 37 years were not well disturbed across the study domain. To overcome the problem of stations' scarcity, the study used a satellite-based rainfall estimate from Climate Hazards Group Infrared Precipitation with Station observation (CHIRPS version 2.0). In the previous study, CHIRPS was compared to other satellite rainfall estimates and reanalysis datasets, and the results revealed that it delivers a good performance compared to other datasets (Nkunzimana et al. 2020). Different studies have evaluated the performance of different datasets across Africa and East Africa in particular and carried out that CHIRPS is likely to deliver reliable and accurate rainfall information than other gridded data (Ayehu et al. 2018; Dinku et al. 2018; Ayugi et al. 2019 ). It delivers rainfall data with a spatial resolution of 0.05 degrees on a daily scale (Funk et al., 2015).

With the perspective of conducting in-depth drought analysis, several methods were utilized. The methods used allowed us to identify all drought years and drought periods and analyse the drought trends across the study area during the period of study.

\section{Methodology}

\subsection{Standardized Precipitation Index (SPI)}

The standardized precipitation index (SPI) is known as one of the tools developed with the core objective of quantifying drought. It enables the monitoring of the drought intensity, frequency, and duration over time in a specific region. It is also used to analyze the periods characterised by abnormal events and allows to identify wet and dry years within historical data. The SPI serves to monitor the drought events by different time scales such as one month, 3 months, 6 months, 12 months, 24 months, etc. The calculation is done by taking the difference of the precipitation from a mean for each particular time scale which is then divided by the standard deviation. This tool was developed by Mc Kree et al. (1993). According to previous studies, the SPI-3 is normally used to assess agricultural droughts, SPI-6 is important in studying hydrological droughts while the SPI-12 and SPI-24 are used in detecting groundwater droughts (Elkollaly et al. 2018). This method is recommended by the World Meteorological Organization (Lü et al. 2017)(Svoboda and Fuchs 2017b) and is widely used for drought analysis. Detailed information about the method is much explained in previous studies (Ayuso et al. 2015; Du et al. 2013; Elkollaly et al. 2018; Zhim et al. 2019).

The classification of wet and dry conditions was calculated based on the SPI values shown in the table 2:

Table 2: Categories of dry and wet conditions based on SPI values

\begin{tabular}{|l|l|}
\hline SPI values & Categories \\
\hline$\geq 2.00$ & Extremely wet \\
\hline $1.50-1.99$ & Severely wet \\
\hline $1.00-1.49$ & Moderately wet \\
\hline-0.99 to 0.99 & Near normal \\
\hline-1.49 to -1.00 & Moderately dry \\
\hline-1.99 to -1.50 & Severely dry \\
\hline$\leq-2.00$ & Extremely dry \\
\hline
\end{tabular}




\subsection{Mann-Kendall and modified Mann Kendall trends test}

The non-parametric Mann-Kendall (MK) statistic test is one of the commonly used tools to detect trends in time series. The Mann Kendall statistical test was employed to analyse the significance of the trend in SPI time series for a period ranging from 1981 to 2017. It served to show the statistical significance with upward and downward trends and its strength depending on the magnitude, the size and the variation of the analysed data (Bevan and Kendall 1971). This method is recommended by the World Meteorological Organisation to check any trend within a given time series. This method has been employed by several researchers to assess rainfall variability and drought monitoring over Africa (Ongoma et al. 2016b; Onyutha et al. 2016; Onyutha and Willems 2017b; Ayugi and Tan 2019; Gebremeskel et al. 2020). A significant level of 5\% was considered and two hypotheses were used to detect the trend. Herein, $\mathrm{Ho}$ expresses the absence of the trend and $\mathrm{Ha}$ evoques the existence of a trend in the data series. Relevant information about this method is detailed in several previous studies ( Ongoma and Chen 2017; Akinsanola et al. 2017; Asfaw et al. 2018; Ayugi and Tan 2018; Byakatonda et al. 2018; Kabanda 2018; Mumo et al. 2019).

On the other side, the Modified Mann Kendall trend test was employed in detecting the trend significance within SPI values. This method is one of the tools that help to reduce the risk of false increasing or decreasing trend induced by the existence of positive or negative autocorrelation in the data (Hamed et al. 1998). It also helps to discriminate multi-scale variability of the unidirectional trends in time series (Sa'adi et al. 2019). Previous studies revealed that the existence of autocorrelation in data can lead to a misinterpretation of the trend significance in time series (Khan et al. 2019; Nashwan et al. 2019). Herein, Modified Mann Kendall helped to detect the significance of the trend in annual and seasonal averaged SPI values generated with 3,6 and 12-months time scales. Relevant details about the Modified Mann Kendall are developed in previous studies (Hamed et al. 1998; Shahid et al. 2014; Khan et al. 2019; Nashwan et al. 2019, Sa'adi et al. 2019).

\subsection{Sen's slope estimator test}

The Sen's slope estimator (Sen, 1968) is used to calculate the magnitude of trends within SPI values. For instance, if a linear trend is present in a time series, then the true slope of the trend is estimated using a Sen-Theil trend line (Sen 1968; Theil 1950), which is an alternative to linear regression and is used in conjunction with the MK test. The slope (Ti) of all data pairs is computed as given in Equation (1).

$T_{i}=\frac{X_{j}-X_{k}}{j-k}$

for $i=1,2,3, \ldots . N$

Where $x_{j}$ and $x_{k}$ are considered as data values at time $j$ and $k,(j>k)$ correspondingly. The median of these $N$ values of $T_{i}$ is represented as Sen's estimator of the slope, which is given by the equation (2): 
$Q_{i}=\left\{\begin{array}{c}T_{\frac{N+1}{2}}, N \text { is odd } \\ \frac{1}{2}\left(T_{\frac{N}{2}}+\frac{T_{\frac{N+2}{2}}}{2}\right), N \text { is even }\end{array}\right.$

Sen's estimator is computed as $Q_{\text {med }}=T_{(N+1) / 2}$ if $N$ appears odd, and it is considered as $Q_{\text {med }}=T_{\frac{N}{2}}+T_{\frac{N+2}{2}}$ if $N$ appears even. Finally, $Q_{\text {med }}$ is calculated by a two-sided test at $100(1-\alpha) \%$ confident interval, which in turn helps to get the true slope through the nonparametric test. A positive value of $Q_{i}$ indicates an increasing trend and a negative value of $Q_{i}$ gives a decreasing trend in time series ( Shang and Yan 2010; Bari et al. 2016 Sharma et al. 2016).

\subsection{Sequential Mann Kendall test (SQMK)}

The SQMK method is used to depict the abrupt change in trend or approximative year of the beginning of the significant trend within the period of study (Bari et al. 2016). In this study, it was used to investigate the trend in the SPI time series and consisted of showing the progressive function $u(t)$ and the backward function $u^{\prime}(t)$ throughout the study. $U(t)$ represents a standardized variable with zero mean. If the progressive and the backward functions cross one another or diverge beyond a given threshold value, the upper confidence limit corresponds to +1.96 while the lower limit corresponds to -1.96 for a $95 \%$ confidential degree. This method was widely applied by different scholars ( Ongoma and Chen 2017; Ayugi et al. 2018).

\section{Results and discussions}

\subsection{Interannual and seasonal variability}

To understand the occurrence of a drought event over Burundi, it is crucial to analyze interannual and seasonal rainfall variability. Fig. 2 (a) exhibits the annual cycle averaged over 37 years ranging from 1981 to 2017. Two main wet seasons (SOND \&MAM) characterise the climatology of Burundi and are regulated by the ITCZ movement (Mutai and Ward, 2000). These two seasons represent more than $70 \%$ of annual rainfall (Table 1). More rainfall is recorded during the MAM season with a peak in April and declining by the end of May. The two wet seasons are separated by a transitional period January-February locally known as the short dry season. During recent decades, this transitional period consistently varies and registers substantial rainfall in some years (MINATTE, 2007). During the short rains season, the rainfall relatively increases from mid-September to reach a peak in November (Fig.2 (a)). This period registres a lot of fluctuations, especially during recent decades. More cases of drought events are registered during the SOND season than the previous season. The northern and eastern parts of Burundi prone to meteorological drought, causing crop failure that directly affects the socio-economic activities and income in the country.

From 1981 the interannual rainfall variability exhibits a consistent decrease specifically from the 1990 decade (Fig.2(b)). 
According to standardized anomaly analysis, the period 1990-2007 registered less rainfall except the year 1997 that registered more rainfall linked to the El-Nino Southern Oscillation event (Ngarukiyimana et al. 2017; Limbu and Guirong) and the year 2006 linked to the positive Indian Ocean Dipole (King'uza and Limbu 2019). The year 1993 was the driest year during the studied period. It was followed by crop failure and famine in many areas over Burundi affecting the livelihood of the population. The period 2000-2007 was characteriSed by agricultural drought especially in the Northern part and eastern part of Burundi(Sabushimike, 2009). The rainfall relatively increases from 2008, however it varies from one season to another as shown in Fig.2(c\&d).

In order to investigate rainfall fluctuations over the seasonal scale, the standardized anomaly of MAM and SOND was analysed. Fig. 2(c) shows the rainfall variability during long rains (MAM) based on standardized anomaly analysis. It can be seen that MAM registered a significant decrease from 1990. From that period it was observed more fluctuations. The driest MAM season was observed during the years 1984, 2000, 2007, 2008 and 2014. The 2000s' decade exhibits a significant decrease, with an exception of the year 2006 corresponding to positive Indian Ocean Dipole (IOD). On the other hand, it is also seen that the short rains period registered significant rainfall decrease from 1990 (Fig. 2 (d)). The driest SOND were recorded in the years 1993, 1996, 1998, 2003 and 2005. These fluctuations are linked to the abnormal atmospheric events associated with rainfall onset (King'uza and Tilwebwa 2019; Limbu and Guirong 2019). The overall analysis of the annual mean and seasonal rainfall exhibited that more rainfall fluctuations started from the 1990s' decade especially in the year 1993. It can be seen more variabilities are observed not only during the short rains but also during the long rains.

The Variability of MAM rainfall is associated not only to ITCZ but also to different drivers such as El Nino Southern Oscillation, Indian Ocean Dipole, Congo basin, and subtropical anticyclone (Mascarene High and Saint Helena (Camberlin and Okoola 2003; King'uza and Tilwebwa 2019).

Fig. 2 The annual cycle of rainfall $(\mathrm{mm})$ and rainfall variability over Burundi during 37 years ranging from 1981 to 2017. (a) represents the climatology (mm), (b) shows annual standardized anomaly (c) represents long rains standardized anomaly and (d) represents the short rains standardized anomaly

\subsection{Evaluation of drought patterns on annual and seasonal scales with SPI time series}

The annual analysis of the SPI index issued from 15 stations exhibited the existence of drought events throughout the study period. Fig.3 (a) shows dry and wet months as generated by SPI-1 averaged over stations. The analysis of generated SPI-1 values showed that among the 28 wet events recorded, 43\% occurred during the 1980s' decade, the 1990 and 2000 decades recorded less wet months, at $21 \%$ and $20 \%$ respectively. The 1990 and 2000 decades experienced more dry months than the previous decades. For 14 dry months generated by SPI-1, 8 events are registered within the period 1990-2000. These two decades are known to be the driest decades over the study domain. Dry conditions were also recorded in neighboring countries specifically Rwanda and Tanzania (Ngarukiyimana et al. 2017b; Chang'a et al. 2017; Idrissa F. Nkurunziza et al. 2019). As shown in the figure, the fluctuations over a 1-month time scale between wet and dry conditions are difficult to depict. 
For that purpose, most of the further analysis was conducted over 3, 6 and 12-month time scale.

Analysis of SPI-3 result averaged over Burundi showed that dry conditions started from the 1990s' decade (Fig.3 (b)). Extreme dry years are 1993, 2000, 2003, and 2005 and correspond to previous findings (MINATTE, 2007; Athanase Nkunzimana et al. 2019). With SPI-3 results it can be sees that the rainfall significantly decreased from the 1990s' decade. This helps to identify agricultural drought that caused the yield failure and the decrease of livestock especially in the northern part of Burundi resulting in more cases of families suffering from hunger.

With SPI_6 and SPI-12 (Fig.3 c\&d), it can be seen that wet conditions occurred during the years 1985, 1986, 1987, 1988, 1989,1998, 2007, 2009, 2011, 2014, and 2015 while dry periods were recorded during 1983, 1993, 1995, 1996, 1998, 2000, 2002, 2003, 2004, 2005, 2006, 2015 and 2016.

The analysis of SPI time series results averaged over the study domain may hide some information about the dry and wet events. For a better understanding of the drought events over Burundi, it is important to analyse the wet and dry conditions over different regions with different topographical unities. Analysis of SPI-6 generated over different regions exhibited that the northern, eastern, and western parts of Burundi experienced more dry periods than other regions. The northern part of Burundi is the most threatened by recurrent drought events and the dry events started from the 1990s' decade. More than 82 dry months were recorded and $86.5 \%$ of these occurred during the period 1990-2000. Among these recorded dry events, 23 were extremely dry and 25 severely dry events, contributing $28 \%$ and $30.4 \%$ of the total records respectively. This area registered 48 moderate wet events where $81.25 \%$ occurred within the 1980s' decade. However, there was no extreme wet event recorded throughout that period. Likewise, the eastern part of Burundi registered 68 dry events, with 6 extremely dry and 18 severely dry events. It is worth noting that the North region used to be the most productive in terms of beans and sorghum production. The occurrence of agricultural drought events has affected livestock production in Burundi and the GDP in general (SABUSHIMIKE 2009). Apart from the two regions that experienced more dry events, the rainfall decreased significantly in the western part of Burundi, especially from the 1990s' decade as well as in the North. About 62 dry events were recorded among them, 9 extreme dry events, and 17 severely dry events where $69.3 \%$ occurred during the 1990 and 2000s' decades. The common characteristic of the three regions is the continuous rainfall decrease from the 1990s. All these regions registered a significant rainfall decrease with an annual mean of less than $1000 \mathrm{~mm}$ (MINATTE 2007).

Contrary to the northern, eastern, and western parts of the study domain; the mountainous part of Burundi recorded more dry events during the 2000s' decade. Among 66 dry events recorded, $46.9 \%$ occurred within the period 2000-2010. From the 12 extreme events, 10 of them occurred during the 2000s' decade. This coincided with the hydrological deficit that affected the socio-economic activities of Burundi ( MINATTE 2007; SABUSHIMIKE 2009). The drought that occurred during the period 2000-2007 caused an alarming decrease in the hydropower at the Rwegura station that provides electricity for over $30 \%$ of Burundi. The mountainous part includes the wettest region, however, during the study period, only 8 extreme wet events were registered. The region recorded more dry events as well as wet events.

The central and the southern parts of Burundi experienced less dry events compared to previous regions. 
Dry and wet events were normally distributed, thus less consecutive dry months leading to drought periods as observed in the North. The central part of Burundi mainly characterized by plateau is known to be one of the regions with less rainfall variability. The rainfall over this region relatively decreases compared to other regions (Nkunzimana et al. 2019b). Although SPI didn't show a specific drought period, the region registered 56 dry events where $26.7 \%$ were extreme dry events. It was characterized by more wet events (71) among which extreme wet months represent $10 \%$.

The southern part of Burundi also experienced low rainfall variability. Previous studies revealed that this region benefits from regular rainfall during SOND as well as during MAM season (Nkunzimana et al. 2020a). SPI-6 exhibits the existence of drought and wet events during the study period, 64 and 66 dry and wet events were recorded respectively. It can be seen that this region registered a very short dry period compared to the northern and eastern regions.

Fig. 3 SPI values showing short term and medium term drought during the period 1981-2017. (a) shows dry and wet periods at one month scale (SPI-1), (b) presents short dry periods at three months scale (SPI-3), (c) shows wet and dry periods at 6 months scale (SPI-6) and (d) represents a medium-dry period at one year scale (SPI-12).

For a better understanding of wet and dry conditions over Burundi, this study analysed the SPI index not only over an annual scale but also over a seasonal scale. The annual and seasonal SPI index of the region that experienced more dry events was investigated. The seasonal analysis enables to uncover information hidden by SPI results averaged on annual scale. The analysis of SPI-3 values at an annual scale over the study domain doesn't clearly show the existence of severe dry or extreme dry events (Fig.4 (a)). However, the seasonal analysis clearly shows that the study domain experienced moderate wet events during MAM (Fig.4 (b)) and extreme dry events during SOND (Fig.4 (c)). SPI-3 results exhibited the existence of rainfall variability with a general decreasing trend starting from the 1990s' decade at both annual and seasonal scales.

The comparison of SPI-3 results at annual mean and seasonal scale in the North showed that extreme drought periods started from the year 1993 up to 2002. This period was followed by a decrease of rainfall in MAM and very low rainfall during SOND (Fig.5 (d,e\&f)). The existence of dry events and persisting decrease of rainfall during SOND directly affected the socio-economic activities of the region and the National economy in general (News 2005). Due to the agricultural drought that leads to extensive famine, the population of the northern province of Burundi was assisted with foodstuffs during 2005, 2006 and 2007 consecutive years. The population also got assistance in 2010 and 2015, when crop production seriously decreased due to dry events (Burundi 2006).

Seasonal analysis over the eastern part of Burundi exhibited the existence of more dry events during both MAM and SOND seasons. The annual SPI-3 results exhibit a general dry period from 2000 to 2010 (Fig.5 (g)). The long rains period experienced wet and dry events. Fig.5 (h) shows variability between wet and dry events. However, the SOND season showed persistent dry events especially over the period 1997 to 2012. During this period, the country experienced high yield failure that affected the livelihood and welfare of the local population (Burundi 2006). 
As stated above, the mountainous region is one of the regions that experienced high rainfall variability in the period 1981-2017 including dry and wet periods. MAM season recorded both extreme wet extreme dry events. The wet events are recorded in 1989 and 1998 while severe dry events occurred from the year 2000. This period was characterised by a persistent rainfall decline from the year 2000 up to 2012. On the other hand, the SOND season experienced more severe dry events alternating with wet events (Fig.4 (i)). More dry events occurred from 2002 to 2012. This resulted in hydrologic deficit leading to water shortage in the Rwegura hydropower reservoir leading a serious electricity shortage in most cities served by the hydropower station ( MINATTE 2007; SABUSHIMIKE 2009).

Fig.4 Comparison between annual and seasonal SPI-3 time series over the North, East and mountainous regions

\subsection{Drought severity and drought intensity patterns}

The SPI indices were used to calculate the drought severity and intensity averaged over 37 years. Fig.5 presents the spatial extension of drought severity and intensity based on 3,6 and 12-month time scales.

The SPI-3 series allowed to locate the regions that experienced more severe dry events. The overall analysis showed that the drought event were extended across the whole study domain. The 3 months SPI values shows that high severe drought events are identified in most of the regions except the south-east region (Fig.5 (a1)). On the other hand, the northern region experienced the highest frequency of severe dry events compared to other regions. The highest severely dry value was -42 elongated with high intensity of -1.68 . Apart from the North, other high severe dry events were identified in the East and the mountainous zone with -38 and -42 respectively (Fig. 5(a1)). The results help to highlight and delineate the regions affected by dry events. Identification of recurrent severe drought events and their respective time is important to monitor the drought intensity and mitigating the losses during the drought periods. Previous experiences showed that the North was prone to recurrent drought events compared to the remaining part of the study domain.

The drought intensity was very high in the plain and surrounding area extending eastward. Considering the spatial drought severity, three main regions experienced severe dry events during the study period compared to other regions. However, the western part recorded the highest drought intensity (-1.7) and low annual total rainfall, the region registered less severe dry events. Most of the severe drought events were identified in the northern and eastern parts of Burundi.

The drought severity extension at a 6-months scale is reduced and the prone area was the North and East parts. A large part of the central plateau, the mountainous region, and the west parts experienced relatively low severe dry events. Herein, the dry events decreased in severity and intensity over the central and the southeast parts of Burundi. This denotes that the only regions under risk of a 6-month drought are the North and East regions (Fig.5 $(\mathrm{a} 2 \& \mathrm{~b} 2))$.

The spatial analysis of severe dry events at a 12-month time scale shows a significant decrease in terms of the frequency of the severity across the country. High severe dry value is recorded in the North and slightly in the west and southwest plains (Fig.5 (a3)). The drought 
intensity significantly decreased in the east and southeast parts. However, the North and the west still experienced moderately high drought intensity as shown in Fig.5 (c3).

The spatial analysis of the cumulative frequency of drought events helped to depict areas that recorded more drought events during the short, medium and long term. The spatial distribution of cumulative frequencies (\%) in terms of extremely, severely and moderately dry events at 3,6 and 12-month time scales. This study found that more severe dry events occurred in the northern part. The three indices, the SPI-3, SPI-6 and SPI-12 results exhibited the existence of a high frequency of extremely dry events in the North part. They registered $5.2 \%, 6.1 \%$ and $7.4 \%$ at 3,6 and 12 respective month' time scales. Other regions recorded less than $3.5 \%$ of extremely dry events reported. The southern part registered the lowest extremely dry frequency, at $1.1 \%$. The northern part which is located in the depression experienced the highest frequency of extremely dry events compared to other topographies. The eastern part registered low extremely dry frequencies. However, it experienced the highest severely dry frequency as well as the North at both 3 and 6 months time scale of SPI analysis. The North registered 5.4\% and 5.2\% while the East recorded 5.2 \% and 5.2\% at 3 and 6-month time scale (Table 3). Most of the study domain experienced a high frequency of moderately dry events. Still, the northeastern part recorded the highest cumulative frequency with $7.9 \%$ at both 3 and 6-month time scales in the North; and $8.8 \%$ and $10.1 \%$ in the East at 3 and 6-month time scale respectively. The central and the western parts recorded the highest frequencies of moderately dry events over SPI_12 with $10.1 \%$ and 8.8\% respectively.

Fig. 5 Spatial patterns of drought severity and intensity over 1981-2017 period using SPI-3, SPI-6 and SPI-12 values

Table 3 Comparison of cumulative frequencies of drought event over different topographical unities based on SPI-3, SPI-6 and SPI-12

\begin{tabular}{|l|l|c|c|c|}
\hline & Region & Extremely dry (\%) & severely dry(\%) & moderately dry(\%) \\
\hline \multirow{4}{*}{ SPI-3 } & North & 5.2 & 5.4 & 7.9 \\
\cline { 2 - 5 } & East & 1.4 & 5.2 & 8.8 \\
\cline { 2 - 5 } & Mount. & 2.7 & 4.7 & 7.2 \\
\cline { 2 - 5 } & Center & 2.7 & 4.3 & 7.4 \\
\cline { 2 - 5 } & West & 2.0 & 4.1 & 7.7 \\
\hline
\end{tabular}




\begin{tabular}{|l|l|l|l|c|} 
& South & 1.1 & 4.3 & 7.4 \\
\hline \multirow{5}{*}{ SPI-6 } & North & 6.1 & 5.2 & 7.9 \\
\cline { 2 - 5 } & East & 0.7 & 5.2 & 10.1 \\
\cline { 2 - 5 } & Mount. & 2.3 & 3.2 & 7.9 \\
\cline { 2 - 5 } & Center & 3.4 & 2.0 & 7.7 \\
\cline { 2 - 5 } & West & 1.8 & 2.5 & 8.1 \\
\cline { 2 - 5 } & South & 0.5 & 5.0 & 8.3 \\
\hline \multirow{5}{*}{ SPI-12 } & North & 7.4 & 5.0 & 6.1 \\
\cline { 2 - 5 } & East & 0.0 & 0.9 & 7.2 \\
\cline { 2 - 5 } & Mount. & 2.9 & 2.5 & 7.2 \\
\cline { 2 - 5 } & Center & 1.6 & 3.4 & 10.1 \\
\cline { 2 - 5 } & West & 0.0 & 4.7 & 8.8 \\
\cline { 2 - 5 } & South & 0.0 & 4.7 & 7.4 \\
\hline
\end{tabular}

\subsection{Spatial analysis of drought duration}

The duration of dry events is very important in determining the severity of the drought over a given region. Fig. 6 presents the spatial distribution of extreme, severe and moderate dry events. From SPI-3 results, it can be seen that the northern part registered more extreme events. For instance, 27 extreme dry events occurred within 6 years (1992-1998). With 6months SPI and 12-month time scales, the driest period started from 1994 up to 1996, and 1994 to February 1997 with 27 and 33 extremely dry events respectively. Thereafter, 19931996 was identified to be the driest period over the time of the study. The drought event seriously affected the local community especially the population of Kirundo and a part of Muyinga provinces. The famine also resulted in more internal migrations. The government launched national solidarity to come in aid of the population that suffered from famine in Kirundo and Muyinga provinces. More foodstuffs were collected across the country supported by international aid and delivered by the World Food Programme (UN Office for the Coordination of Humanitarian Affairs, 2005; MINATTE 2007).

In the North region, more than 24 extreme dry months were recorded within a period of 6 years ranging from the year 1993 to 1999. During this period, apart from the yield failure, the drought events seriously impacted lakes' ecosystem causing the hydrologic deficit of most lakes located in the region. Lakes Gacamirindi and Kanzigiri both located in the depression of the North later dried up and causing more losses in terms of lake ecosystems (NTAKIMAZI 2006).

The intensification in frequencies of recurrent extreme and severe dry events in the mountainous regions caused a deficit in groundwater leading to the decrease of water level in the hydropower reservoir of Rwegura (SABUSHIMIKE 2009).

From the findings presented in Fig.6 (d), more than $70 \%$ of the study domain experienced severe dry events. The highest duration in terms of severe dry events is registered in the North and the mountainous regions. Most of the plateau region experienced relatively high frequency. The lowest severe dry duration is found in the southeastern part (Fig.6 (d)). This expresses that most of the study domain experienced dry events though the frequency and intensity were different. 
The drought duration significantly decreased at 6 months and 12 months time scales. At a 6month time scale, the highest frequency was recorded in the North and eastern parts where 23 and 21 severe dry months were registered respectively. The southwest part also presented relatively long severe dry events. From SPI-3, SPI-6, and SPI-12, it can be seen that the west-south region experienced less dry events compared to the northeastern part.

The analysis of the number of months that registered moderate dry events presented that most of the study domain experienced more moderate dry events. The longest duration of moderate dry events was registered in the North and East parts with 69 and 66 moderately dry months respectively.

Overall analysis showed that the North region experienced a long drought period. The SPI-3 results showed that the region recorded 89 dry months from September 1992 to February 2000 with density average of -1.57 . Within the same period, the SPI-6 and SPI-12 established that the region recorded 88 and 89 dry months with a drought intensity average of -1.69 and 1.68 respectively (Table 4$)$.

Contrary to the North region, based on the 3-months SPI, the East region recorded 80 dry months within the period 2003-2010, where 29 consecutive dry months occurred during the years 2004-2006 and 20 consecutive months in 2007-2009. These two periods were characterised by crop failure accompanied by foodstuff decrease and migration of several people to Tanzania.

Based on 3-months, 6 months and 12 months SPI results, the western part of Burundi recorded a few dry months although is it known as a dry region (MINATTE 2007). The drought period was relatively short with very low intensity. The longest dry period was the year 1993 where all the 12 months were identified as dry months. The period 2005-2007 and 2016-2017 recorded 5 and 9 dry months respectively.

The mountainous region normally considered as the wettest region recorded 64 dry months where more than $85 \%$ occurred during the years 2000-2007. According to the 3-months SPI, the region experienced short consecutive dry periods. 7 consecutive dry months were recorded from September 1993 to April 1994, 9 months from September 2002 to July 2003, 8 dry months from August 2003 to April 2004, 9 months from October 2005 to July 2006 and 8 months for the year 2006-2007. However, both 3-months, 6-months and 12-month time scales showed a very low intensity compared to the remaining regions (Table 4). The central and southern parts of Burundi registered a relatively short drought compared to the remaining regions. The central region recorded 59 dry months while the south recorded 56 dry months.

The center experienced dry periods during the year 1993 with 7 consecutive dry months, the year 2000 with 7 consecutive dry months and the period 2005-2006 with 11 dry months. On the other hand, the southern region recorded 6 months from October 1993 to April 1994. The longest dry year was the year 2000 where 11 months were identified dry. Contrary to the remaining regions, although the central and southern part registered dry periods with a relatively high drought intensity, the impact on agriculture was relatively low. However, it would be noted that the last decade registered more fluctuation leading to rainfall decline as seen in Fig.2(b). 
Fig. 6 Spatial patterns of drought duration by the number of months based on 3,6 and 12month time scales for extremely dry, severely dry and moderately dry for the period 19812017 averaged over Burundi

Table 4 Comparison of drought duration, severity, intensity of occurrence and peak values for different regions

\begin{tabular}{|c|c|c|c|c|c|c|c|}
\hline \multirow{5}{*}{ SPI-3 } & Region & North & East & West & Center & $\begin{array}{l}\text { Mount. } \\
\text { Region }\end{array}$ & South \\
\hline & Duration & 89 & 85 & 69 & 59 & 64 & 56 \\
\hline & Severity & -140.75 & -34.33 & -98.75 & -85.38 & -58.36 & -68.94 \\
\hline & Intensity & -1.58 & -0.4 & -1.6 & -1.4 & -0.9 & -1.2 \\
\hline & Peak & -2.8 & -3.23 & -3.67 & -3.8 & -3.47 & -2.81 \\
\hline \multirow{5}{*}{ SPI-6 } & Region & North & East & West & Center & $\begin{array}{l}\text { Mount. } \\
\text { Region }\end{array}$ & South \\
\hline & Duration & 88 & 90 & 71 & 38 & 47 & 52 \\
\hline & Severity & -148.96 & -82.21 & -61.36 & -65.16 & -36.25 & -60.67 \\
\hline & Intensity & -1.69 & -0.9 & -0.8 & -1.7 & -0.7 & -1.16 \\
\hline & Peak & -2.95 & -2.88 & -3.42 & -3.88 & -2.5 & -2.14 \\
\hline \multirow{5}{*}{ SPI-12 } & Region & North & East & West & Center & $\begin{array}{l}\text { Mount. } \\
\text { Region }\end{array}$ & South \\
\hline & Duration & 89 & 77 & 36 & 36 & 63 & 45 \\
\hline & Severity & -149.27 & -80.07 & 0 & 0 & -30.65 & -39.37 \\
\hline & Intensity & -1.68 & -1.03 & 0 & 0 & -0.48 & -0.86 \\
\hline & Peak & -2.81 & -2.51 & -1.91 & -1.9 & -1.78 & -1.86 \\
\hline
\end{tabular}

\subsection{Spatial trend analyses of annual and seasonal drought with SPI time series}

The Mann Kendall test and Sen's slope statistical test were employed to detect spatiotemporal trends across the study domain based on 3,6 and 12 months SPI. The spatial trend analysis helped to identify the regions with increasing or decreasing trends over annual and seasonal time scales. Regions with a significant increasing trend correspond to the part threatened by recurrent drought events (Fig. 7 (a1,b2\&c3)). The trend features helped in the identification of regions prone to dry or wet events. Previous studies on annual rainfall variability showed a decreasing trend in the northeastern and western part of the study domain (Nkunzimana et al. 2019).

The analysis of the SPI-3 series at annual scale showed a significant increasing trend in the northern and eastern parts of Burundi and a decreasing trend in the plateau and the southeastern region (Fig.7 (a1) \& Table 5)). During the long rains season, the north and east parts experienced a positive increasing trend and most of the study domain had a positive trend. Contrary to the long rains season, the southern and northeastern parts of Burundi experienced a negative trend during the short rains season with a positive increasing trend in the North and over the mountainous region (Fig.7 (b1\&c1)). Likewise, the SPI-6 and SPI-12 annual time scale exhibited an increasing trend over the northeastern and western parts of the study domain. It was found that both SPI-6 and SPI-12 series exhibited a decreasing trend in the central region. However, the SPI-12 result showed a significant decreasing trend in the south (Fig.7 (a3)). From this, it can be deduced that the central and southern parts are 
unlikely to experience a long period of drought compared to other regions. According to SPI6 and SPI-12 output, during the long rains season, the positive trend was recorded in the North and East with a relatively positive increase across the plateau and a negative trend in the South. On the contrary, during the short rains season, there was a significant increasing trend over most of the study domain except over the central part of the mountainous zone(Fig.7 (c3)).

Overall analysis exhibits a positive trend in the northeastern parts mostly corresponding to the regions that experienced more drought events during the 1990 and 2000 decades (SABUSHIMIKE 2009). The most disastrous dry period occurred within the period 19931996 and 200-2006, periods characterised by high rainfall decline as found shown with the standardized anomaly. The dry period had a serious negative impact on crop production and the economy of the country in general. As stated, the population of Burundi relies on rain-fed agriculture which contributes $39.6 \%$ of the national GDP and provides more than $95 \%$ of food supply (Burundi 2018). The northern part of Burundi commonly known as "Bugesera" that extends to Rwanda experienced a decreasing trend in both annual and seasonal scales during the recent decades (Ngarukiyimana et al. 2016; Nkunzimana et al. 2019). Thereafter, the occurrence of one to three dry months during the crop growing season would automatically cause yield failure leading to a decrease in foodstuff production.

The Mann Kendall results enabled the detection of the significance of the drought trend based on SPI analyses where the Z-score exceeding the magnitude of critical value at $5 \%$ of the significance level denoted a positive or negative trend. The spatial analysis of SPI values helped to depict the changes in trend across the study domain over the period 1981-2017. The Sen's slope statistics test results exhibited a negative slope in the stations located over the northern and eastern parts. A negative slope was also registered over the south part of the study domain (Table 5). However, the western part presented a positive slope during annual and seasonal scales (SOND). During the long and short rains, more than $60 \%$ of the territory showed a negative slope. Moreover, the regions that registered a negative slope are those which experienced more dry events over the studied period. The southern and southwest regions experienced a relatively decreasing trend. The region experienced less dry events, although they were likely to record medium duration drought.

In the perspective of deepening drought trend analysis to reduce any misinterpretations of the drought trend significance, the study compared the Mann Kendall and modified Mann Kendall trend tests. It is worth to recall that the Modified Mann Kendall allows to reduce the short and long term autocorrelation in the data (Nashwan et al. 2019, Khan et al. 2019). The Fig. 8 shows the comparison between annual and seasonal Mann Kendall and Modified Mann Kendall trend results of SPI values generated with 3,6 and 12-month time scales. The analysis of the annual trend showed that the Modified Mann Kendall exhibited a very significant decreasing trend over the eastern and southeast parts of the study domain; however, the Mann Kendall did not depict the negative significant trend in the southeast part at 3 months scale (Fig. 8(a1\&11) \&table 5)). Besides, the north and south parts presented a significant decreasing trend according to the Modified Mann Kendall while the simple Mann Kendall depicted a relative increasing trend at 6 months scale (Fig.8 (a2\&l2)) and, likewise the modified Mann Kendall allowed to depict a significant decreasing trend over the North and East part (Fig.8\&13). The assessment of drought trend at annual scale with Mann Kendall exhibited a significant trend in most of the region except in the South at 3 and 6-months scales. However, the Modified Mann Kendall exhibited a significant trend in the East, and a part of North and the north-west regions at 3 months scale. At 6 and 12 months scales a significant trend is recorded in the North, the East and the mountainous region. Modified 
Mann Kendal didn't depict any significant trend over the West region at both annual and seasonal observations. However, both Mann Kendall and Modified Mann Kendall showed a positive trend in that region.

Contrary to the observed significant trend of annual drought, the observation of the MAM season with Mann Kendall trend results revealed that only the North and the East regions registered a significant increasing trend at both 3,6 and 12-month time scales. The mountainous regions presented a significant increasing trend during the short rains season.

On the other hand, the Modified Mann Kendall exhibited a significant decreasing trend in the North, the East, the southern regions. The mountainous region showed a very significant decreasing trend during the long rain season at both 3,6 and 12-month time scale and a very significant decreasing trend during short rains season at 12-month scale

From Table 5, it can be seen that during the SOND season, the Mann Kendall trend test showed a very significant increasing trend in the North at both time scales, a very significant increasing trend in the East at 12-month time scale as well as the mountainous region. However, the Modified Mann Kendal presented a very significant decreasing trend observed over the North at both time scales, while the East, the mountainous region and the south parts showed a very significant decreasing trend at 12-month time scale.

From the observations, it is found that the regions that presented a very significant increasing trend with the Mann Kendall and a very significant decreasing trend with Modified Mann Kendall are regions that recorded more dry periods.

Fig. 7 Comparison of spatial distribution of Mann Kendall and modified Mann Kendall trends in annual and seasonal SPI values generated with 3,6 and 12-month timescales averaged on the period 1981-2017 over Burundi

Table 5. Annual and seasonal positive significant trend observed with Mann Kendall and annual and seasonal negative significant trend with Modified Mann Kendall at 3, 6 and 12months scales (**denote very significant and * denotes significant at confidence level $0.5 \%)$

\begin{tabular}{|c|c|c|c|c|c|c|c|c|c|c|}
\hline & \multicolumn{10}{|c|}{ Mann Kendall trend test } \\
\hline & \multirow{3}{*}{ Station } & \multicolumn{3}{|c|}{ Annul } & \multicolumn{3}{|c|}{ MAM } & \multicolumn{3}{|c|}{ SOND } \\
\hline & & & & & & & & & & \\
\hline & & SPI-3 & SPI-6 & SPI-12 & SPI-3 & SPI-6 & SPI-12 & SPI-3 & SPI-6 & SPI-12 \\
\hline \multirow{3}{*}{ North } & Kirundo & $0.88 * *$ & $0.88 * *$ & $0.89 * *$ & $0.78 * *$ & $0.8^{* * *}$ & $0.85 * *$ & $0.81 * *$ & $0.84 * *$ & $0.88 * *$ \\
\hline & Muyinga & 0.2 & 0.25 & 0.18 & 0.03 & -0.13 & -0.05 & -0.02 & 0.07 & 0.24 \\
\hline & Nyamuswaga & $0.72 * *$ & $0.66 * *$ & $0.52 * *$ & 0.22 & 0.14 & 0.23 & 0.27 & $0.34^{*}$ & $0.64 * *$ \\
\hline \multirow{3}{*}{ East } & Musasa & 0.04 & 0.06 & 0.04 & -0.03 & -0.1 & -0.09 & -0.3 & -0.35 & 0 \\
\hline & Kinyinya & $0.68 * *$ & $0.71 * *$ & $0.65 * *$ & $0.65 * *$ & $0.63 * *$ & $0.46^{*}$ & $0.45^{*}$ & 0.21 & $0.63 * *$ \\
\hline & cankuzo & 0.27 & 0.34 & 0.18 & 0.11 & -0.05 & -0.07 & -0.13 & -0.03 & 0.27 \\
\hline Center & Gitega & 0.08 & 0.17 & 0.2 & -0.04 & 0.09 & 0.06 & 0.05 & 0.01 & 0.13 \\
\hline \multirow{4}{*}{$\begin{array}{l}\text { Mount. } \\
\text { Region }\end{array}$} & Gisozi & $0.48^{*}$ & $0.38^{*}$ & $0.38^{*}$ & 0.14 & 0.19 & 0.11 & $0.44 *$ & $0.34 *$ & $0.5^{* *}$ \\
\hline & Rwegura & 0.27 & 0.3 & 0.19 & 0.19 & -0.06 & 0.02 & 0.06 & 0.08 & 0.24 \\
\hline & Bugarama & -0.2 & -0.2 & -0.19 & 0.01 & -0.18 & -0.28 & -0.05 & -0.12 & -0.18 \\
\hline & Tora & $0.34 *$ & $0.34 *$ & 0.3 & 0.06 & 0.08 & 0.15 & 0.11 & 0.15 & $0.34^{*}$ \\
\hline West & Bujumbura & $0.35^{*}$ & $0.49^{*}$ & $0.44^{*}$ & -0.06 & 0.19 & $0.44^{*}$ & 0.1 & 0.23 & 0.5 \\
\hline
\end{tabular}




\begin{tabular}{|c|c|c|c|c|c|c|c|c|c|c|}
\hline \multirow{6}{*}{ South } & Mparambo & 0.27 & 0.19 & 0.2 & -0.1 & -0.06 & 0.08 & 0.28 & 0.23 & 0.22 \\
\hline & Nyanzalac & -0.02 & -0.01 & -0.3 & -0.11 & -0.23 & 0.1 & 0.11 & 0.03 & 0.05 \\
\hline & Makamba & 0.03 & 0.15 & 0.17 & 0.11 & 0.13 & 0.08 & -0.31 & -0.2 & 0.17 \\
\hline & \multicolumn{10}{|c|}{ Modified Mann Kendall trend test } \\
\hline & \multirow{2}{*}{ Station } & \multicolumn{3}{|c|}{ Annual } & \multicolumn{3}{|c|}{ MAM } & \multicolumn{3}{|c|}{ SOND } \\
\hline & & SPI-3 & SPI-6 & SPI-12 & SPI-3 & SPI-6 & SPI-12 & SPI-3 & SPI-6 & SPI-12 \\
\hline \multirow{3}{*}{ North } & Kirundo & -0.97 & -1.03 & -0.7 & 1.77 & 0.74 & -0.82 & -0.96 & -1.47 & -0.65 \\
\hline & Muyinga & -0.95 & -1.03 & -0.6 & -0.58 & -0.51 & -1.32 & -1.05 & $-1.79 *$ & -0.73 \\
\hline & Nyamuswaga & 0 & $-3.28 * *$ & $\begin{array}{l}- \\
2.89 * *\end{array}$ & $-2.1 * *$ & 0 & $-2.2 * *$ & $-2.22 * *$ & $\begin{array}{l}- \\
2.76^{* *}\end{array}$ & $\begin{array}{l} \\
2.94 * *\end{array}$ \\
\hline \multirow{3}{*}{ East } & Musasa & $-3.19 * *$ & -1.34 & -1.11 & $-1.66^{*}$ & -1.16 & -1.09 & -0.79 & -1.007 & -0.87 \\
\hline & Kinyinya & -0.83 & -1.4 & -1.26 & -1.29 & -1.45 & -1.38 & -0.84 & $-1.56^{*}$ & -1.39 \\
\hline & cankuzo & $-1.89 *$ & $-2.39 * *$ & $-2.3 * *$ & $\overline{5} .21 * *$ & -1.9 & $-9.02 * *$ & 0.27 & -0.85 & $\begin{array}{l}- \\
3.36 * *\end{array}$ \\
\hline Center & Gitega & -1.32 & -0.95 & -0.87 & -0.69 & -0.09 & -1.25 & -1.2 & $-1.71 *$ & -0.61 \\
\hline \multirow{4}{*}{$\begin{array}{l}\text { Mount. } \\
\text { Region }\end{array}$} & Gisozi & 1.34 & 1.05 & 1.19 & -1.09 & 0.5 & 0.27 & 2.47 & 1.13 & 1.5 \\
\hline & Rwegura & -0.22 & -0.22 & -0.42 & -1.03 & -0.7 & -1.01 & 0.17 & 0.001 & 0 \\
\hline & Bugarama & -0.73 & -0.77 & -0.87 & $\overline{2} .03^{* *}$ & -1.17 & -0.94 & 0.039 & -0.66 & -0.66 \\
\hline & Tora & $-2.07 * *$ & $-2.7 * *$ & $\begin{array}{l}- \\
2.13 * *\end{array}$ & $\begin{array}{l} \\
3.29 * *\end{array}$ & $3.58 * *$ & $-2.13 * *$ & -0.02 & -1.18 & $3.16^{* *}$ \\
\hline \multirow{2}{*}{ West } & Bujumbura & 0.19 & -0.06 & 0.53 & -0.71 & 0.27 & -0.15 & 0.74 & 0.17 & 0.32 \\
\hline & Mparambo & 1.34 & 0.95 & 1.63 & 0.44 & 1.65 & 1.11 & 0.4 & 0.28 & 1.25 \\
\hline \multirow[t]{2}{*}{ South } & Nyanzalac & $-1.6^{*}$ & $-1.55^{*}$ & $\begin{array}{l} \\
2.05 * *\end{array}$ & 0.14 & -0.77 & $-2.62 * *$ & $-1.87 *$ & $-2.9 * *$ & $-2 * *$ \\
\hline & Makamba & 0.96 & 0.9 & 1.131 & 0.58 & 1.103 & 0.83 & 1.36 & 0 & 1.05 \\
\hline
\end{tabular}

For Mann Kendall trend test: Trend $>=0.5=$ very significant

$$
\text { Trend }>=0.3<0.5=\text { significant }
$$

For Modified Mann Kendall trend test: $\mathrm{z}<=-2=$ very significant

$$
\mathrm{z}<=-1.5>-2=\text { significant }
$$

The Sequential Mann Kendall (SQMK) of annual SPI-3 was also employed to depict the abrupt point of the trend throughout the SPI time series. The SPI-3 series was chosen in other to monitor the years that registered more dry events impacting the growing season, which is normally of 3 months period for each. The SQMK analysis over the annual time scale exhibited a positive increasing trend reaching the first abrupt point in 1990. This year coincided with the beginning of occurrent dry events. The trend relatively increased up to the year 2000 and slightly decreased until the year 2012. During the decreasing phase, the forward and backward sequential abrupt points occurred during 2004, 2005, 2006, 2007, 2008, 2011 and 2012.

The period 1993-2005 was characterised by an increasing trend and corresponded to the driest period specifically in the northern part of the studied area as shown in time series and spatial figures (Fig. 5). 
Likewise, the SQMK test of SPI-3 applied to the long rains season showed a positive and increasing trend from 1986 up to 1997 from where the trend slightly decreases. The forward and backward abrupt points were recorded in 1988, 1989,1991, 1993, 2000, 2001, 2007, 2008, 2009, 2010, 2012, and finally in 2016. These successive abrupt points denoted the existence of variability in rainfall where dry and wet events occur alternatively. During the short rains season, the increasing trend started from 1989 to 2001. The intersection of forward and backward sequences occurred in 1993, 1994, 2001, 2002, 2005, 2007, 2008, 2009, and 2010. Thereafter, the SQMK results showed that more rainfall fluctuations started from the 1990s decade, a period coinciding with the first abrupt point of forward and backward sequential statistic. The 1990s decade was also identified to be the starting period of an increasing in rainfall variability resulting in more extremes weather events across East Africa (Ogwang et al. 2015; Ngarukiyimana et al. 2017c; Chang'a et al. 2017; Ongoma et al. 2018)

It was found that more abrupt points occurred after the year 2005. However, according to previous SPI time series analyses, it was found that more dry events occurred within the period 1993-2005. Thus, the presence of more abrupt points after 2005 denoted a high rainfall variability owing to the occurrence of the short dry and short wet events. The variability is experienced at both annual and seasonal time scales specifically during the short rains season.

The overall analysis of drought events at annual and seasonal scales converged on the existence of recurrent dry periods specifically over the North and East regions. However, the evaluation of drought intensity and frequency showed that the western and southern parts are likely to dry events althought they presented less dry months compared to the remaining regions. In addition, the western and southern parts exhibited a positive slope while the North and the East regions presented a negative slope and positive trend.

\subsection{Atmospheric factors associated with the drought frequency over the study domain}

Understanding the causes behind the occurrence of drought events requires a deepen analysis of the linkage existing between dry years and atmospheric circulation anomalies within the study period. For that purpose, the study used the composite analysis method to investigate the significance of the anomalies.

The composite analysis is one of the methods used by several scholars in analysing the circulation anomalies over different regions including East Africa (Ayugi et al. 2018; Limbu and Guirong 2019; Kantamla B. Mafuru and Guirong 2020). For that purpose, this study investigated the circulation anomalies during dry years. Fig. 8 shows the composite of zonal and meridional winds anomalies during the wet and dry years within 37 years. The comparison between composite zonal and meridional wind anomalies in wet years and dry years allowed depicting the anomalies behind the occurrence of recurrent drought events. During the long rain season, the study domain was dominated by southeasterly moist winds at the lower lever (F8. (a)) while the upper level is dominated by westerly winds (Fig8.(c)). The winds at lower atmosphere flow from the West of the Indian Ocean westwards and the moisture embedded over the ocean contributes to convection that takes place over Central East Africa. The convection is the result of the convergence between the moist air generated by southeasterly winds and the moist air from Congo.

On the other hand, during dry years, moist air mass from the Indian ocean is simulated by Indian monsoon, while a limited dry air mass across Central East Africa with less chance of advection and ascending motion at the lower level(Fig.8(b)). This situation is linked to the 
negative phase of IOD characterized by descending motion as found by previous studies (Ayugi et al. 2018; King'uza and Tilwebwa 2019; Kantamla and Guirong 2020). At the upper-pressure level, Central east Africa is dominated by trade winds resulting from the walker circulation cell over the Indian Ocean as shown by the figure (Limbu and Guirong 2019). The zonal and meridional wind patterns over Central East Africa is linked to ITCZ movement as well as the fluctuations in surface temperatures of the Indian Ocean that varies the winds patterns and SST varies from year to year.

During the short rains season, Central East Africa experiences the passage of ITCZ and is swept by Northeasterly winds. It is worth recalling that Northerly winds are cold and dry with a low capacity of providing rainfall. Therefore, the rainfall result from different factors mainly existing water bodies, the topography especially the moist air mass from the Congo basin (Fig.8(e)). However, the upper atmosphere is dominated by southeast winds exhibit the absence or weak southeasterly winds, thus absence or less rainfall over the study domain(Fig.8(g)). This phenomenon is linked to ENSO and IOD which are strongly connected to SST anomalies in the Indian Ocean and affect inter-annual variability of rainfall over East Africa(Mutai and Ward, 2000; Ogwang et al.2015; Ngarukiyimana et al. 2018).

During the dry season, Central East Africa is dominated by weak southeasterly winds from the Indian Ocean and air mass from the Congo basin. However, there is a low chance of convective pr advective rain because the walker circulation cell over Indian Ocen was weakened by the ENSO phenomenon(Limbu and Guirong 2019).

Fig. 8 Composites of zonal and meridional winds anomalies (vector in $\mathrm{ms}^{-1}$ ) during wet and dry years overaged over long rains and short rains season. The blue box shows the study domain.

The analysis of composite velocity potential and divergence anomalies was conducted to investigate whether there exist any relationships between wind convergence/divergence patterns at lower and upper pressure levels. This allowed depicting areas with horizontal wind convergence or divergence during dry years. Fig. 9 represents the composite velocity potential and divergent winds anomalies during short rains and long rains season in dry years at 850 $\mathrm{hPa}$ and $200 \mathrm{hPa}$. During the long rains season, most of Central East Africa including Burundi was characterised by divergent winds at both lower-pressure and upper-pressure levels whereas the winds convergence was located over the western Indian Ocean. Therefore, this situation corresponds to the absence of convection/advection of moist air that may generate wet conditions over the study domain. Likewise, the eastern part of the Indian Ocean was also characterised by divergent winds and reveals the weakness of the Walker circulation cell due to ENSO(Fig.9(a\&b)). This coincides with the findings of scholars who studied the circulation anomaly over Tanzania located in the East of Burundi (Limbu and Guirong 2019; Kantamla Biseke Mafuru and Guirong 2020).

At the upper level, the situation reversed over the eastern Indian Ocean towards Indonesian Archipelago. This situation coincides with the positive phase of the Indian Ocean Dipole (IOD) characterised by raising warm sea surface water in the west Indian Ocean and cold water in the South-East Indian Ocean. The divergence in the upper level implies the existence of convergent winds at the lower level (Ayugi et al. 2018). However, the center of convergent winds was located over the Western part of the Indian Ocean southward. The 
ascending limb of the local Indian Ocean Walker circulation generated rainfall conditions over the Indian ocean and specifically the south part of Africa.

During the short rains season, the center of convergence is located over the western Indian Ocean covering southern African countries including the southern part of Tanzania, Zambia, Mozambique, Malawi (Fig. 10 (c)) while most of Central East Africa is dominated by divergent winds with significant decrease centered over Burundi. The ascending air parcels over the western Indian Ocean are deflected to the southern part of Africa. It can be seen that the flow converges at lower levels southward owing to ascending limbs over the southern part of Africa. Centers of low negative velocity potential correspond to divergent outflow.

Contrary to the situation observed during long rains, the northern Indian Ocean was also covered by diverging wind corresponding to the weakening of the Indian monsoon. This means that the local Walker circulation cell became strong over the northern Indian Ocean while the west south Indian experience ascending limb, with possibilities of generating rains. However, the part including Burundi doesn't benefit from rain conditions due to descending limb northward(Fig.9(c)).

At the upper level, the situation reversed, the Northern part of Africa and India were dominated by strong converging winds where the significant velocity potential appeared in the Arabian sea. The southern part experienced descending limbs proving the existence of convergence over the lower level. The influence of positive IOD reflected the ascending limb of the local walker circulation cell over the Eastern Indian Ocean. However, Central east Africa still experiencing descending limbs. The amplitude of the velocity potential became stronger over the area of strong convergence both at a lower level and upper level.

Fig. 9 Composite of velocity potential (colored with contours) and divergence winds (vectors in $\mathrm{ms}^{-1}$ ) anomalies during dry years at 850 and $200 \mathrm{hPa}$. The green box shows the study domain.

Analysis of the correlation between rainfall and ENSO during long rains season allowed to depict whether there is a relationship between the occurrence of dry years and ENSO. Fig.10(a) shows that there exists a positive correlation between the Nino index and rainfall during the MAM season $(\mathrm{R}=0.41)$. It There exists a significant correlation between rainfall and the Nino index within the period 1993 to 2005 corresponding to the driest period over Burundi. There is an explicit correlation between rainfall and positive ENSO year (1997) and La Nina years $(2000,2004)$. Likewise, the correlation between SOND season rainfall and the Nino index was also positive with $\mathrm{R}=0.39$ (Fig. 10 (b)). Contrary to what is observed during the MAM season, although the rainfall and Nino index correlates, there is a high fluctuation during the SOND season. The net correlation between rainfall and Nino event is identified during the years $(1997,2015)$ and the correlation during La Nina years occurred in 1998.

The correlation between MAM rainfall events and dipole mode index (DMI) exhibited that there is a negative correlation with $\mathrm{R}=-0.05$ (Fig. 10(c)). However, the years 1990-1992 show a net correlation, while most of the remaining years don't show a significant correlation.

Fig. 10(d) shows a positive correlation between SOND rainfall and dipole mode index with a correlation coefficient $R=0.66$. The correlation is significant from 1992 to 1998, from 2003 to 2010, and from 2015 to 2017. The correlation shows that the positive phase of the Indian Ocean Dipole (IOD) contributes to increased convection over the western part of the Indian 
Ocean that affects Central East Africa rainfall. However, the correlation between rainfall and the negative phase of IOD is linked to the absence of rainfall over the study domain. This situation is also linked to anomalous pressure gradient with eastern zonal wind anomalies and SST over the Indian Ocean as revealed by previous studies( Ogwang et al. 2015b; Limbu and Guirong 2019).

Fig.10 Correlation between MAM rainfall and Nino Index (a), SOND rainfall and Nino Index (b), MAM rainfall and DMI Index (c), SOND rainfall and DMI Index (d)

\section{Conclusions}

Drought as one of climate extreme events is among the most dangerous natural hazards considering the losses it induces across many regions of the globe. Burundi is facing recurrent drought events, especially during the last three decades. To assess the drought frequency intensity and duration, the study used the Standardized Precipitation Index (SPI) at 3, 6 and 12-month time scales over 37 years ranging from 1981 to 2017.

The SPI time series analysis helped to determine dry events over the study period. It was found that the driest period started within the 1990s decade. The drought events were unevenly distributed over the study domain. The northern part experienced the longest dry period between 1992 to 2000 . That period was accompanied by high losses in terms of human and socio-economic activities. The eastern part also recorded more dry events especially during the period 2000-2010. Apart from the two regions, the rainfall decline was also observed in the mountainous region resulting in more dry months accompanied by hydrologic and food shortage.

The comparison of drought frequencies on annual and seasonal scales across different regions of Burundi revealed that more extremely and severely dry events occurred during the short rain season (SOND) and the frequency intensity changed with the topography.

The overall analysis of drought duration showed that the north region registered more dry events compared to other regions. On one hand, the North region experience more extreme and severely dry events at both 3, 6 and 12-month time scales. In that region, almost $100 \%$ of extremely and severely dry events occurred within 8 years (1993-2000). On the other hand, the East region and the plateau registered more moderately dry events at 6 and 12-month time scales.

The central and west regions experienced less severe dry events with a short duration, albeit with high frequency, though the drought intensity was very high. These two regions experienced less severe and moderate dry events.

The analysis of drought trend with Mann Kendall statistics showed that the North and East parts experienced a very significant increasing trend at both 3,6 and 12- month time scales spatial drought trends at both annual and seasonal scales. However, Sen's slope showed that the two regions had a negative slope while the western and southern parts presented a positive trend. Likewise, the Modified Mann Kendall showed that the northern and eastern parts had a very significant decreasing trend. The mountainous region is also experienced a significantly decreasing trend at both 3,6 and 12-month time scales.

The sequential Mann Kendall results enabled to observe the rainfall variability and the first abrupt point occurred in 1990 a year that coincided with the beginning of recurrent dry period 
events. More abrupt points were observed within a short period, thus 7 abrupt points were identified between 2003 and 2013.

The dry years are associated with the weakening of the Walker circulation cell that is related to the rise of sea surface temperature over the eastern Pacific ocean. The fluctuations over the Pacific ocean directly affect wind circulation over the Indian Ocean. Central East Africa normally experiences dry conditions during the negative phase of the Indian Ocean Dipole.

This work is the first comprehensive study on drought assessment and trend analysis over Burundi. It will serve as a reference in future studies on drought patterns in terms of frequencies, intensity and duration. It will help policymakers in setting up early warning drought system and mitigation measures of the drought impacts on the population and socioeconomy activities in general. The factors associated with the occurrence of drought events over Burundi will be assessed in the next work.

Acknowledgment The authors wish to express sincere thanks to Nanjing University of Information Science and Technology (NUIST) for making available all materials needed for research. Special thanks go to the Geographical Institute of Burundi (IGEBU) and the Climate Hazards Group Infrared Precipitation with Station observation (CHIRPS) for making available the datasets used in this work.

Funding This study was supported by the National Natural Science Foundation of China (No.41271410 and No. 41971340).

Conflict of interest/Competing interests The authors declare that they have no conflicts or competing interests relevant to the content of this article.

Authors' Contributions Conceptualization: Nkunzimana Athanase; Methodology: Nkunzimana Athanase, Mohamed Abdallah Ahmed Alriah; Formal analysis and investigation: Nkunzimana Athanase, Vuguziga Floribert, Sarfo Isaac; Writing - original draft preparation: Nkunzimana Athanase, Xu Zhihui; Writing - review and editing: Vuguziga Floribert, Brian Odhiambo Ayugi, Sarfo Isaac; Funding acquisition: Bi Shuoben, visualization; Resources: Bi Shuoben; Supervision: Bi Shuoben, Wang Guojie.

Availability of data and material The datasets and material used during the current study are available from the corresponding author on reasonable request.

Code availability Available after request

Ethics approval Not applicable

Consent to participate Not applicable

Consent for publication Not applicable

\section{References}

Abro, M.I., Zhu, D., Wei, M., Majidano, A.A., Khaskheli, M.A., Ul Abideen, Z., Memon, M.S. (2019) Hydrological appraisal of rainfall estimates from radar, satellite, raingauge and satellite-gauge combination on the Qinhuai River Basin, China. Hydrol. Sci. J. 64, 
1957-1971. https://doi.org/10.1080/02626667.2018.1557335

Ahmed, K., Shahid, S., Nawaz, N. (2018) Impacts of climate variability and change on seasonal drought characteristics of Pakistan. Atmos. Res. https://doi.org/10.1016/j.atmosres.2018.08.020

Akinsanola, A. A., \& Ogunjobi, K. O. (2017) Recent homogeneity analysis and long-term spatio-temporal rainfall trends in Nigeria. Theoretical and Applied Climatology, 128(12), 275-289. https://doi.org/10.1007/s00704-015-1701-X

Ali, S. M., Khalid, B., Akhter, A., Islam, A., \& Adnan, S. (2020) Analyzing the occurrence of floods and droughts in connection with climate change in Punjab province, Pakistan. Natural Hazards, 103(2), 2533-2559. https://doi.org/10.1007/s11069-02004095-5

Asfaw, A., Simane, B., Hassen, A., Bantider, A. (2018) Variability and time series trend analysis of rainfall and temperature in northcentral Ethiopia: A case study in Woleka sub-basin. Weather Clim. Extrem. 19, 29-41. https://doi.org/10.1016/j.wace.2017.12.002

Ayehu, G.T., Tadesse, T., Gessesse, B., Dinku, T. (2018) Validation of new satellite rainfall products over the Upper Blue Nile Basin, Ethiopia. Atmos. Meas. Tech. 11, 1921-1936. https://doi.org/10.5194/amt-11-1921-2018

Ayugi, B., Tan, G., Rouyun, N., Zeyao, D., Ojara, M., Mumo, L., Babaousmail, H., Ongoma, V. (2020) Evaluation of meteorological drought and flood scenarios over Kenya, East Africa. Atmosphere (Basel). 11(3). https://doi.org/10.3390/atmos11030307

Ayugi, B., Tan, G., Ullah, W., Boiyo, R., \& Ongoma, V. (2019) Inter-comparison of remotely sensed precipitation datasets over Kenya during 1998-2016. Atmos. Res. 225, 96-109. https://doi.org/10.1016/j.atmosres.2019.03.032

Ayugi, B.O., Tan, G. (2019) Recent trends of surface air temperatures over Kenya from 1971 to 2010. Meteorol. Atmos. Phys. 131, 1401-1413. https://doi.org/10.1007/s00703-0180644-Z

Ayugi, B.O., Tan, G., Ongoma, V., Mafuru, K.B. (2018) Circulations Associated with Variations in Boreal Spring Rainfall over Kenya. Earth Syst. Environ. 2, 421-434. https://doi.org/10.1007/s41748-018-0074-6

Ayuso, J.L., Ayuso-Ruiz, P., García-Marín, A.P., Estévez, J., Taguas, E. V. (2015) Local Analysis of the Characteristics and Frequency of Extreme Droughts in Málaga Using the SPI (Standardized Precipitation Index) 167-179. https://doi.org/10.1007/978-3-31912754-5_13

Baramburiye, Miriam Kyotalimye, T.S.T., Waithaka, and M. (2013) East African agriculture and climate change: Burundi. IFPRI 34. https://doi.org/DOI: 10.13140/2.1.3072.7044

Bari, S. H., Rahman, M. T. U., Hoque, M. A., \& Hussain, M. M. (2016) Analysis of seasonal and annual rainfall trends in the northern region of Bangladesh. Atmospheric Research, 176-177, 148-158. https://doi.org/10.1016/j.atmosres.2016.02.008

Bayissa, Y., Tadesse, T., Demisse, G., Shiferaw, A. (2017) Evaluation of satellite-based rainfall estimates and application to monitor meteorological drought for the Upper Blue Nile Basin, Ethiopia. Remote Sens. 9(7). https://doi.org/10.3390/rs9070669

Benlin, S.H.I., Xinyu, Z.H.U., Yunchuan, H.U., Yanyan, Y. (2017) Drought characteristics of Henan province in 1961-2013 based on Standardized Precipitation Evapotranspiration Index 27, 311-325. https://doi.org/10.1007/s11442-017-1378-4

Bevan, J.M., Kendall, M.G. (1971) Rank Correlation Methods. Stat. https://doi.org/10.2307/2986801

Bi, Shuoben, Bi, Shengjie, Chen, C., Nkunzimana, A., Li, Y., Wu, W. (2016) Spatial characteristics analysis of drought disasters in North China during the Ming and Qing Dynasties. Nat. Hazards Earth Syst. Sci. Discuss. https://doi.org/10.5194/nhess-2016-249 
Black, E. (2005) The relationship between Indian Ocean sea-surface temperature and East African rainfall. Philosophical Transactions of the Royal Society A: Mathematical, Physical and Engineering Sciences, 363(1826), 43-47. https://doi.org/10.1098/rsta.2004.1474

Burundi, G. (2018) PLAN NATIONAL DE DEVELOPPEMENT DU BURUNDI PND BURUNDI 2018-2027. PNUD-Burundi. URL http://www.presidence.gov.bi/wpcontent/uploads/2018/08/PND-Burundi-2018-2027-Version-Finale.pdf (accessed 9.11.20).

Burundi, G. (2006) Burundi: Government sets up food security fund. ECC Platf. Libr. URL https://library.ecc-platform.org/news/burundi-government-sets-food-security-fund (accessed 9.10.20).

Byakatonda, J., Parida, B.P., Moalafhi, D.B., Kenabatho, P.K. (2018) Analysis of long term drought severity characteristics and trends across semiarid Botswana using two drought indices. Atmos. Res. https. 213, 492-508.

https://doi.org/10.1016/j.atmosres.2018.07.002

Camberlin, P., Okoola, R.E. (2003) The onset and cessation of the "“ long rains " in eastern Africa and their interannual variability. Theor. Appl. Climatol. 54, 43-54. https://doi.org/10.1007/s00704-002-0721-5

Camberlin, P., Janicot, S., Poccard, I. (2001) Seasonality and atmospheric dynamics of the teleconnection between African rainfall and tropical sea-surface temperature: Atlantic vs. ENSO. Int. J. Climatol. https://doi.org/10.1002/joc.673

Cattani, E., Merino, A., Guijarro, J.A., Levizzani, V. (2018) East Africa Rainfall trends and variability 1983-2015 using three long-term satellite products. Remote Sens. 10, 1-26. https://doi.org/10.3390/rs10060931

Chang'a, L.B., Kijazi, A.L., Luhunga, P.M., Ng'ongolo, H.K., Mtongor, H.I. (2017) Spatial and Temporal Analysis of Rainfall and Temperature Extreme Indices in Tanzania. Atmos. Clim. Sci. 07, 525-539. https://doi.org/10.4236/acs.2017.74038

Dinku, T., Funk, C., Peterson, P., Maidment, R., Tadesse, T., Gadain, H., \& Ceccato, P. (2018) Validation of the CHIRPS satellite rainfall estimates over eastern Africa. Q. J. R. Meteorol. Soc. 144, 292-312. https://doi.org/10.1002/qj.3244

Du, J., Fang, J., Xu, W., Shi, P. (2013) Analysis of dry/wet conditions using the standardized precipitation index and its potential usefulness for drought/flood monitoring in Hunan Province, China. Stoch. Environ. Res. Risk Assess. https://doi.org/10.1007/s00477-0120589-6

Elkollaly, M., Khadr, M., Zeidan, B. (2018) Drought analysis in the Eastern Nile basin using the standardized precipitation index. Environ. Sci. Pollut. Res. https://doi.org/10.1007/s11356-016-8347-9

Forootan, E., Khaki, M., Schumacher, M., Wulfmeyer, V., Mehrnegar, N., van Dijk, A.I.J.M., Brocca, L., Farzaneh, S., Akinluyi, F., Ramillien, G., Shum, C.K., Awange, J.,

Mostafaie, A. (2019) Understanding the global hydrological droughts of 2003-2016 and their relationships with teleconnections. Sci. Total Environ.

https://doi.org/10.1016/j.scitotenv.2018.09.231

Gebrechorkos, S.H., Hülsmann, S., Bernhofer, C. (2018) Evaluation of multiple climate data sources for managing environmental resources in East Africa. Hydrol. Earth Syst. Sci. 22, 4547-4564. https://doi.org/10.5194/hess-22-4547-2018

Gebremeskel Haile, G., Tang, Q., Leng, G., Jia, G., Wang, J., Cai, D., ... Zhang, Q. (2020) Long-term spatiotemporal variation of drought patterns over the Greater Horn of Africa. Science of the Total Environment, 704. https://doi.org/10.1016/j.scitotenv.2019.135299

Gebremeskel, G., Tang, Q., Sun, S., Huang, Z., Zhang, X., Liu, X. (2019) Droughts in East Africa: Causes, impacts and resilience. Earth-Science Rev. 
https://doi.org/10.1016/j.earscirev.2019.04.015

Guo, H., Bao, A., Liu, T., Jiapaer, G., Ndayisaba, F., Jiang, L., Kurban, A., De Maeyer, P. (2018) Spatial and temporal characteristics of droughts in Central Asia during 19662015. Sci. Total Environ. https://doi.org/10.1016/j.scitotenv.2017.12.120

Haile, G. G., Tang, Q., Hosseini-Moghari, S. M., Liu, X., Gebremicael, T. G., Leng, G., ... Yun, X. (2020) Projected Impacts of Climate Change on Drought Patterns Over East Africa. Earth's Future, 8(7). https://doi.org/10.1029/2020EF001502

Hamed, K. H., \& Ramachandra Rao, A. (1998) A modified Mann-Kendall trend test for autocorrelated data. Journal of Hydrology, 204(1-4), 182-196. https://doi.org/10.1016/S0022-1694(97)00125-X

Hastenrath, S. (2007) Circulation mechanisms of climate anomalies in East Africa and the equatorial Indian Ocean. Dyn. Atmos. Ocean. 43, 25-35. https://doi.org/10.1016/j.dynatmoce.2006.06.002

He, Y., Ye, J., Yang, X. (2015) Analysis of the spatio-temporal patterns of dry and wet conditions in the Huai River Basin using the standardized precipitation index. Atmos. Res. https://doi.org/10.1016/j.atmosres.2015.06.022

Hesam, M., Roshan, G., Grab, S. W., \& Shabahrami, A. R. (2021) Comparative assessment of farmers' perceptions on drought impacts: the case of a coastal lowland versus adjoining mountain foreland region of northern Iran. Theoretical and Applied Climatology, 143(1-2), 489-503. https://doi.org/10.1007/s00704-020-03432-9

Huang, S., Huang, F. (2012) Spatial-temporal variations of dominant drought/flood modes and the associated atmospheric circulation and ocean events in rainy season over the east of China. J. Ocean Univ. China. https://doi.org/10.1007/s11802-012-1813-1

Indeje, M., Semazzi, F.H.M. (2000) Enso signals in East African Rainfall seasons. International journal of Climatology, 20, 19-46.doi:10.1002/(SICI)10970088(200001)20:1<19::AID-JOC449>3.0.CO;2-0, http://dx.doi.org/10.1002/(SICI)1097-008 46, 19-46.

Ionita, M., Scholz, P., Chelcea, S. (2016) Assessment of droughts in Romania using the Standardized Precipitation Index. Nat. Hazards. https://doi.org/10.1007/s11069-0152141-8

Jemai, S., Kallel, A., Abida, H. (2018) Drought distribution using the standardized precipitation index: case of Gabes Basin, South Tunisia. Arab. J. Geosci. 11(23). https://doi.org/10.1007/s12517-018-4053-x

Kabanda, T. (2018) Long-term rainfall trends over the Tanzania coast. Atmosphere (Basel). 9. https://doi.org/10.3390/atmos9040155

Khadr, M. (2017) Temporal and spatial analysis of meteorological drought characteristics in the upper Blue Nile river region. Hydrol. Res. 48(1), 265-276 .

https://doi.org/10.2166/nh.2016.194

Khan, N., Shahid, S., Ismail, T. bin, \& Wang, X. J. (2019) Spatial distribution of unidirectional trends in temperature and temperature extremes in Pakistan. Theoretical and Applied Climatology, 136(3-4), 899-913. https://doi.org/10.1007/s00704-0182520-7

King'uza, P., Tilwebwa, S. (2019) Inter-annual variability of March to May rainfall over Tanzania and its association with atmospheric circulation anomalies. Geogr. Pannonica 23, 147-161. https://doi.org/10.5937/gp23-22430

Li, X., Zhang, Q., Ye, X. (2013) Dry/wet conditions monitoring based on TRMM rainfall data and its reliability validation over poyang lake basin, China. Water (Switzerland). https://doi.org/10.3390/w5041848

Limbu, P.T.S., Guirong, T. (2019) Relationship between the October-December rainfall in Tanzania and the Walker circulation cell over the Indian Ocean. Meteorol. Zeitschrift 28, 
453-469. https://doi.org/10.1127/metz/2019/0939

Liu, X., Xu, Z., Liu, B. (2009) Spatio-temporal characteristics of standardized precipitation index in the Taihu basin during 1951-2000. Wuhan Univ. J. Nat. Sci. https://doi.org/10.1007/s11859-009-0611-0

Lopes, A. V., Chiang, J.C.H., Thompson, S.A., Dracup, J.A. (2016) Trend and uncertainty in spatial-temporal patterns of hydrological droughts in the Amazon basin. Geophys. Res. Lett. https://doi.org/10.1002/2016GL067738

Lü, M., Wu, S.-J., Chen, J., Chen, C., Wen, Z., Huang, Y. (2017) Changes in extreme precipitation in the Yangtze River basin and its association with global mean temperature and ENSO. Int. J. Climatol. https://doi.org/10.1002/joc.5311

Lyon, B. (2014) Seasonal drought in the Greater Horn of Africa and its recent increase during the March-May long rains. J. Clim. https://doi.org/10.1175/JCLI-D-13-00459.1

Mafuru, Kantamla B., Guirong, T. (2020) The influence of ENSO on the upper warm temperature anomaly formation associated with the March-May heavy rainfall events in Tanzania. Int. J. Climatol. 40, 2745-2763. https://doi.org/10.1002/joc.6364

Mafuru, Kantamla Biseke, Guirong, T. (2020) Causes of the upper-level warm temperature anomaly (UWTA) associated with March-May heavy rainfall in Tanzania. Atmos. Res. 242, 105016. https://doi.org/10.1016/j.atmosres.2020.105016

Mahajan, D.R., Dodamani, B.M. (2015) Trend Analysis of Drought Events Over Upper Krishna Basin in Maharashtra. Aquat. Procedia. https://doi.org/10.1016/j.aqpro.2015.02.163

Mohammed, S., Alsafadi, K., Al-Awadhi, T., Sherief, Y., Harsanyie, E., \& El Kenawy, A. M. (2020) Space and time variability of meteorological drought in Syria. Acta Geophysica, 68(6), 1877-1898. https://doi.org/10.1007/s11600-020-00501-5

Mpelasoka, F., Awange, J.L., Zerihun, A. (2018) Influence of coupled ocean-atmosphere phenomena on the Greater Horn of Africa droughts and their implications. Sci. Total Environ. 610-611, 691-702. https://doi.org/10.1016/j.scitotenv.2017.08.109

Musonda, B., Jing, Y., Iyakaremye, V., Ojara, M. (2020) Analysis of Long-Term Variations of Drought Characteristics Using Standardized Precipitation Index over Zambia. Atmosphere (Basel). 11, 1268. https://doi.org/10.3390/atmos11121268

Mutai, C.C., Ward, M.N. (2000) East African rainfall and the tropical circulation/convection on intraseasonal to interannual timescales. J. Clim. 13, 3915-3939. https://doi.org/10.1175/1520-0442(2000)013<3915:EARATT>2.0.CO;2

Mwangi, E., Wetterhall, F., Dutra, E., Di Giuseppe, F., \& Pappenberger, F. (2014) Forecasting droughts in East Africa. Hydrology and Earth System Sciences, 18(2), 611620. https://doi.org/10.5194/hess-18-611-2014

Nashwan, M.S., Shahid, S., Abd Rahim, N. (2019) Unidirectional trends in annual and seasonal climate and extremes in Egypt. Theor. Appl. Climatol. 136, 457-473. https://doi.org/10.1007/s00704-018-2498-1

News, P. (2005) Burundi: Thousands affected by drought return home. Pambazuka News. URL https://www.pambazuka.org/human-security/burundi-thousands-affected-droughtreturn-home (accessed 9.10.20).

Ngarukiyimana, J.P., Fu, Y., Yang, Y., Ogwang, B.A., Ongoma, V., Ntwali, D. (2018) Dominant atmospheric circulation patterns associated with abnormal rainfall events over Rwanda, East Africa. Int. J. Climatol. https://doi.org/10.1002/joc.5169

Ngarukiyimana, J., Tan, G., Ongoma, V., Ogwang, B., Vuguziga, F. (2016) Application of ZIndex in analysis of recent March-May Drought over Rwanda.

Nicholson, S.E. (2015) Long-term variability of the East African "short rains" and its links to large-scale factors. Int. J. Climatol. https://doi.org/10.1002/joc.4259

Nicholson, S.E. (2014) A detailed look at the recent drought situation in the Greater Horn of 
Africa. J. Arid Environ. 103, 71-79. https://doi.org/10.1016/j.jaridenv.2013.12.003

Nkunzimana, A., Bi, S., Abdallah, M., Alriah, A., Zhi, T., Awan, N., Kur, D. (2020a)

Diagnosis of meteorological factors associated with recent extreme rainfall events over

Burundi. Atmos. Res. 244, 105069. https://doi.org/10.1016/j.atmosres.2020.105069

Nkunzimana, A., Bi, S., Alriah, M.A.A., Zhi, T., Kur, N.A.D. (2020b) Comparative Analysis of the Performance of Satellite-Based Rainfall Products Over Various Topographical Unities in Central East Africa: Case of Burundi. Earth Sp. Sci. 7(5). https://doi.org/10.1029/2019EA000834

Nkunzimana, A., Bi, S., Jiang, T., Wu, W., Abro, M.I. (2019) Spatiotemporal variation of rainfall and occurrence of extreme events over Burundi during 1960 to 2010. Arab. J. 12(5). Geosci. 12. https://doi.org/10.1007/s12517-019-4335-y

Nkurunziza I.F., Tan Guirong, Jean Paul Ngarukiyimana, C.S. (2019) Influence of the Mascarene High on October-December Rainfall and their Associated Atmospheric Circulation Anomalies over Rwanda. J. Environ. Agric. Sci. 20, 1-20.

NTAKIMAZI, G. (2006) ETUDE SECTORIELLE : LES ECOSYSTEMES NATURELS HUMIDES. URL

file://C:/Users/Athanase/Downloads/Ecosytemes_humides_et_changements_climatique s1.pdf (accessed 9.14.20).

Ogwang, B.A., Ongoma, V., Xing, L., Ogou, F.K. (2015c) Influence of mascarene high and Indian Ocean dipole on East African extreme weather events. Geogr. Pannonica 19, 6472. https://doi.org/10.5937/GeoPan1502064O

Ogwang, B.A., Chen, H., Tan, G., Ongoma, V., Ntwali, D. (2015) Diagnosis of East African climate and the circulation mechanisms associated with extreme wet and dry events: A study based on RegCM4. Arab. J. Geosci. 8, 10255-10265. https://doi.org/10.1007/s12517-015-1949-6

Okpara, J.N., Afiesimama, E.A., Anuforom, A.C., Owino, A., Ogunjobi, K.O. (2017) The applicability of Standardized Precipitation Index: drought characterization for early warning system and weather index insurance in West Africa. Nat. Hazards. https://doi.org/10.1007/s11069-017-2980-6

Ongoma, V., Chen, H., \& Omony, G.W. (2018) Variability of extreme weather events over the equatorial East Africa, a case study of rainfall in Kenya and Uganda. Theor. Appl. Climatol. 131, 295-308. https://doi.org/10.1007/s00704-016-1973-9

Ongoma, V., Chen, H. (2017) Temporal and spatial variability of temperature and precipitation over East Africa from 1951 to 2010. Meteorol. Atmos. Phys. 129, 131-144. https://doi.org/10.1007/s00703-016-0462-0

Ongoma, V., Chen, H., Gao, C., Nyongesa, A.M., Polong, F. (2018) Future changes in climate extremes over Equatorial East Africa based on CMIP5 multimodel ensemble. Nat. Hazards 90, 901-920. https://doi.org/10.1007/s11069-017-3079-9

Ongoma, V., Chen, H., Omony, G.W. (2016b) Variability of extreme weather events over the equatorial East Africa, a case study of rainfall in Kenya and Uganda. Theor. Appl. Climatol. 131(1-2), 295-308. https://doi.org/10.1007/s00704-016-1973-9

Ongoma, V., Guirong, T., Ogwang, B., Ngarukiyimana, J. (2015) Diagnosis of Seasonal Rainfall Variability over East Africa: A Case Study of 2010-2011 Drought over Kenya $11,13-21$.

Onyutha, C., Tabari, H., Taye, M.T., Nyandwaro, G.N., Willems, P. (2016) Analyses of rainfall trends in the Nile River Basin. J. Hydro-Environment Res. 13, 36-51. https://doi.org/10.1016/j.jher.2015.09.002

Onyutha, C., Willems, P. (2017a) Space-time variability of extreme rainfall in the River Nile basin. Int. J. Climatol. 37, 4915-4924. https://doi.org/10.1002/joc.5132

Onyutha, C., Willems, P. (2017b) Influence of spatial and temporal scales on statistical 
analyses of rainfall variability in the River Nile basin. Dyn. Atmos. Ocean. 77, 26-42. https://doi.org/10.1016/j.dynatmoce.2016.10.008

Otto, F.E.L., Boyd, E., Jones, R.G., Cornforth, R.J., James, R., Parker, H.R., Allen, M.R. (2015) Attribution of extreme weather events in Africa: a preliminary exploration of the science and policy implications. Clim. Change. 132(4), 531-543.

https://doi.org/10.1007/s10584-015-1432-0

Ou, C., Hao, X. (2018) Agriculture drought and food security monitoring over the horn of Africa (HOA) from space, in: 2018 7th International Conference on AgroGeoinformatics, Agro-Geoinformatics 2018. https://doi.org/10.1109/AgroGeoinformatics.2018.8476128

Philippon, N., Camberlin, P., Moron, V., Boyard-Micheau, J. (2015) Anomalously wet and dry rainy seasons in Equatorial East Africa and associated differences in intra-seasonal characteristics. Clim. Dyn. 45, 2101-2121. https://doi.org/10.1007/s00382-014-2460-6

Polong, F., Chen, H., Sun, S., Ongoma, V. (2019) Temporal and spatial evolution of the standard precipitation evapotranspiration index (SPEI) in the Tana River Basin, Kenya. Theor. Appl. Climatol. 138, 777-792. https://doi.org/10.1007/s00704-019-02858-0

Pramudya, Y., Onishi, T., Senge, M., Hiramatsu, K., Nur, P.M.R., Komariah, K. (2019) Evaluation of recent drought conditions by standardized precipitation index and potential evapotranspiration over Indonesia. Paddy Water Environ. 17(3), 331-338. https://doi.org/10.1007/s10333-019-00728-z

Qaiser, G., Tariq, S., Adnan, S., Latif, M. (2021) Evaluation of a composite drought index to identify seasonal drought and its associated atmospheric dynamics in Northern Punjab, Pakistan. J. Arid Environ. https://doi.org/10.1016/j.jaridenv.2020.104332

Sa'adi, Z., Shahid, S., Ismail, T., Chung, E.S., Wang, X.J. (2019) Trends analysis of rainfall and rainfall extremes in Sarawak, Malaysia using modified Mann-Kendall test.

Meteorol. Atmos. Phys. https://doi.org/10.1007/s00703-017-0564-3

SABUSHIMIKE, J M. (2009) Amelioration des capacités nationales et locales de prevention et de gestion des risques liés aux catastrophes et de gestion durable de l'environnement en vue de proteger les ecosystemes et les populations vulnerables.

https://www.eartheval.org/sites/ceval/files/evaluations/382 Amelioration des capacites nationales et locales de prevention et de gestion des risques.pdf (Accessed 9.16.2020)

Sen, P.K. (1968) Estimates of the Regression Coefficient Based on Kendall's Tau. J. Am. Stat. Assoc. 63(324), 1379-1389. https://doi.org/10.1080/01621459.1968.10480934

Shan, L., Zhang, L., Song, J., Zhang, Y., She, D., Xia, J. (2018) Characteristics of dry-wet abrupt alternation events in the middle and lower reaches of the Yangtze River Basin and the relationship with ENSO. J. Geogr. Sci. https://doi.org/10.1007/s11442-018$\underline{1540-7}$

Shang, H., Yan, J. (2010) Trend analysis of extreme precipitation in the northwestern Highlands of Ethiopia with a case study of Debre Markos 8587-8605. https://doi.org/10.5194/hessd-7-8587-2010

Shanko, D., Camberlin, P. (1998) The effects of the southwest Indian ocean tropical cyclones on Ethiopian drought. Int. J. Climatol. https://doi.org/10.1002/(SICI)10970088(1998100)18:12<1373::AID-JOC313>3.0.CO;2-K

Sharma, C. S., Panda, S. N., Pradhan, R. P., Singh, A., \& Kawamura, A. (2016) Precipitation and temperature changes in eastern India by multiple trend detection methods. Atmospheric Research, 180, 211-225. https://doi.org/10.1016/j.atmosres.2016.04.019

Shi, B., Zhu, X., Hu, Y., Yang, Y. (2017) Drought characteristics of Henan province in 19612013 based on Standardized Precipitation Evapotranspiration Index. J. Geogr. Sci. https://doi.org/10.1007/s11442-017-1378-4

Svoboda, M.D., Fuchs, B.A. (2017a) Handbook of drought indicators and indices, in: 
Drought and Water Crises: Integrating Science, Management, and Policy, Second Edition. https://doi.org/10.1201/b22009

Svoboda, M.D., Fuchs, B.A. (2017b) Handbook of drought indicators and indices, in:

Drought and Water Crises: Integrating Science, Management, and Policy, Second

Edition. https://doi.org/10.1201/b22009

Theil, H. (1950) A rank-invariant method of linear and polynomial regression analysis, Part I. Proc. R. Netherlands Acad. Sci.

Tosunoglu, F., Kisi, O. (2017) Trend Analysis of Maximum Hydrologic Drought Variables Using Mann-Kendall and Şen's Innovative Trend Method. River Res. Appl. https://doi.org/10.1002/rra.3106

Uddin, M.J., Hu, J., Islam, A.R.M.T., Eibek, K.U., Nasrin, Z.M. (2020) A comprehensive statistical assessment of drought indices to monitor drought status in Bangladesh. Arab. J. Geosci. 13. https://doi.org/10.1007/s12517-020-05302-0

UN Office for the Coordination of Humanitarian Affairs (2005) Burundi: La famine sévit dans deux provinces du Burundi - Gouvernement . reliefweb. URL https://reliefweb.int/report/burundi/burundi-la-famine-sévit-dans-deux-provinces-duburundi-gouvernement (accessed 9.20.20).

Wang, W., Guo, B., Zhang, Y., Zhang, L., Ji, M., Xu, Y., ... Zhang, Y. (2021) The sensitivity of the SPEI to potential evapotranspiration and precipitation at multiple timescales on the Huang-Huai-Hai Plain, China. Theoretical and Applied Climatology, 143(1-2), 87-99. https://doi.org/10.1007/s00704-020-03394-y

Winkler, K., Gessner, U., Hochschild, V. (2017) Identifying droughts affecting agriculture in Africa based on remote sensing time series between 2000-2016: Rainfall anomalies and vegetation condition in the context of ENSO. Remote Sens. 9(8). https://doi.org/10.3390/rs9080831

Wu, J., Zhou, L., Mo, X., Zhou, H., Zhang, J., Jia, R. (2015) Drought monitoring and analysis in China based on the Integrated Surface Drought Index (ISDI). Int. J. Appl. Earth Obs. Geoinf. 41, 23-33. https://doi.org/10.1016/j.jag.2015.04.006

Wu, Y., Wu, S.Y., Wen, J., Xu, M., Tan, J. (2016) Changing characteristics of precipitation in China during 1960-2012. Int. J. Climatol. 36(3), 1387-1402. https://doi.org/10.1002/joc.4432

Zeleke, T.T., Giorgi, F., Diro, G.T., Zaitchik, B.F. (2017) Trend and periodicity of drought over Ethiopia. Int. J. Climatol. https://doi.org/10.1002/joc.5122

Zhai, J., Mondal, S.K., Fischer, T., Wang, Y., Su, B., Huang, J., Tao, H., Wang, G., Ullah, W., Uddin, M.J. (2020) Future drought characteristics through a multi-model ensemble from CMIP6 over South Asia. Atmos. Res. 246, 105111. https://doi.org/10.1016/j.atmosres.2020.105111

Zhim, S., Larabi, A., Brirhet, H. (2019) Analysis of precipitation time series and regional drought assessment based on the standardized precipitation index in the Oum Er-Rbia basin (Morocco). Arab. J. Geosci. https://doi.org/10.1007/s12517-019-4656-X

Zhou, L., Wu, J., Mo, X., Zhou, H., Diao, C., Wang, Q., Chen, Y., Zhang, F. (2017) Quantitative and detailed spatiotemporal patterns of drought in China during 2001-2013. Sci. Total Environ. 589, 136-145. https://doi.org/10.1016/j.scitotenv.2017.02.202 


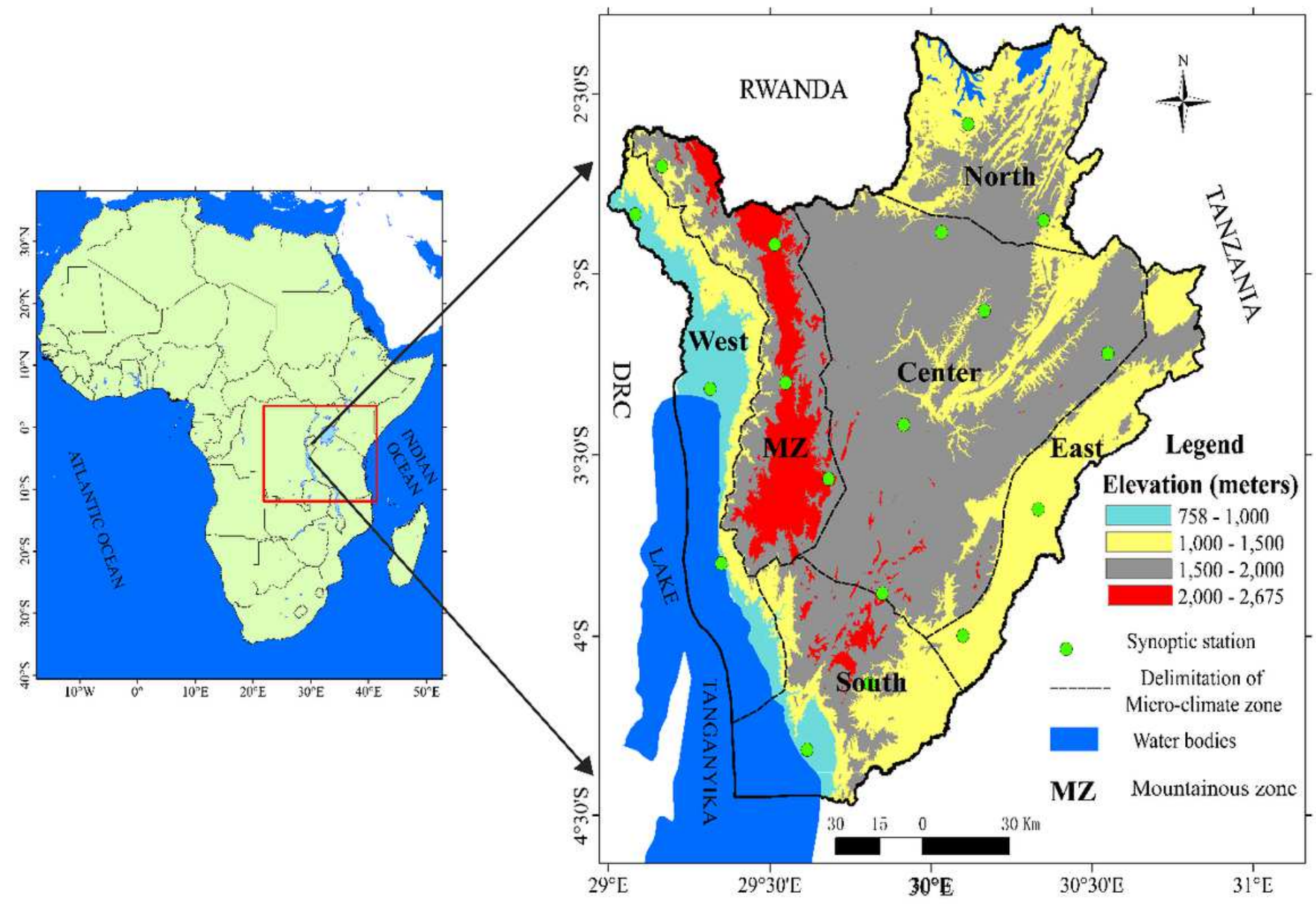

Figure 1

Map of Africa with CEA in the red box (left), the topographical elevation of Burundi with meteorological stations and delimitation of different microclimate zones (right) 

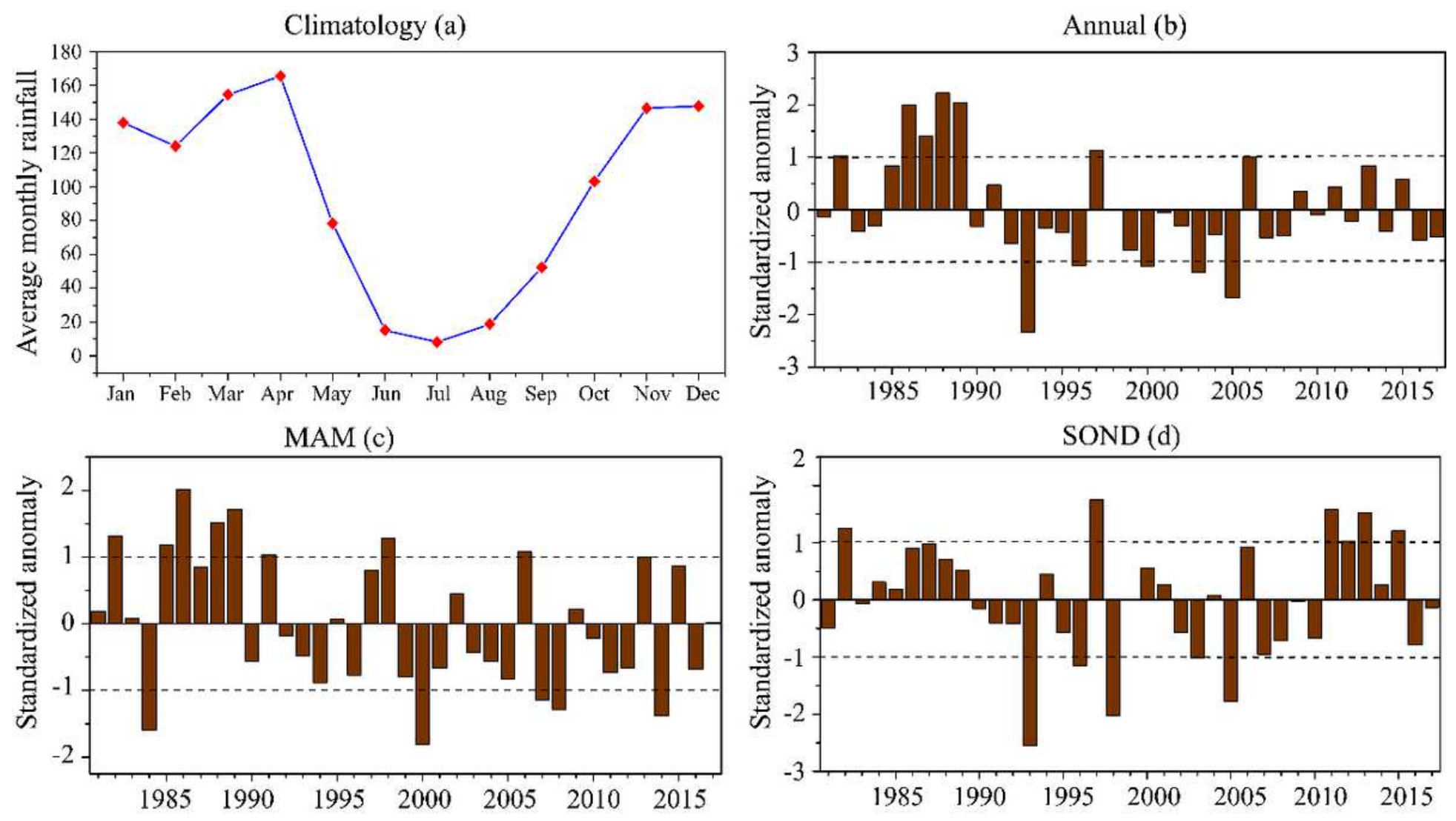

Figure 2

The annual cycle of rainfall $(\mathrm{mm})$ and rainfall variability over Burundi during 37 years ranging from 1981 to 2017. (a) represents the climatology ( $\mathrm{mm}$ ), (b) shows annual standardized anomaly (c) represents long rains standardized anomaly and (d) represents the short rains standardized anomaly 

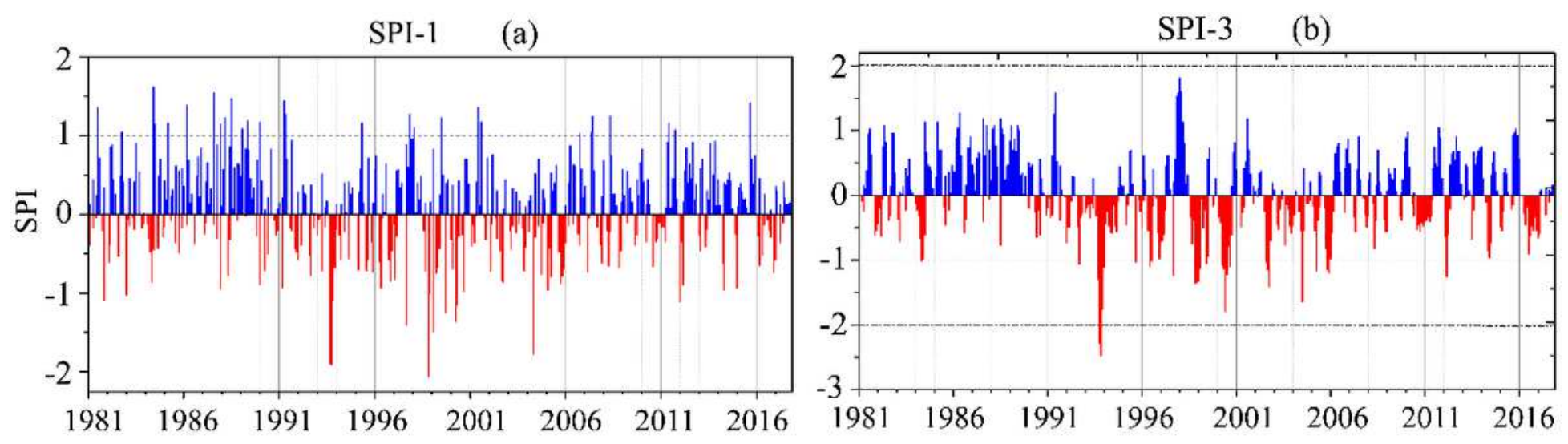

SPI-6 (c)
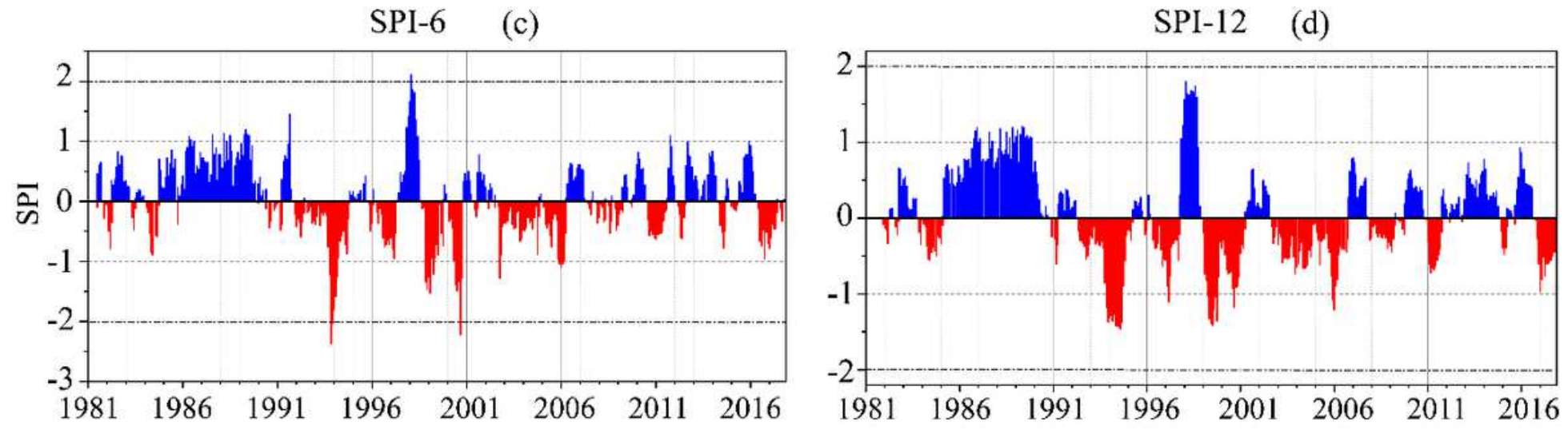

\section{Figure 3}

SPI values showing short term and medium term drought during the period 1981-2017. (a) shows dry and wet periods at one month scale (SPI-1), (b) presents short dry periods at three months scale (SPI-3), (c) shows wet and dry periods at 6 months scale (SPI-6) and (d) represents a medium-dry period at one year scale (SPI-12). 

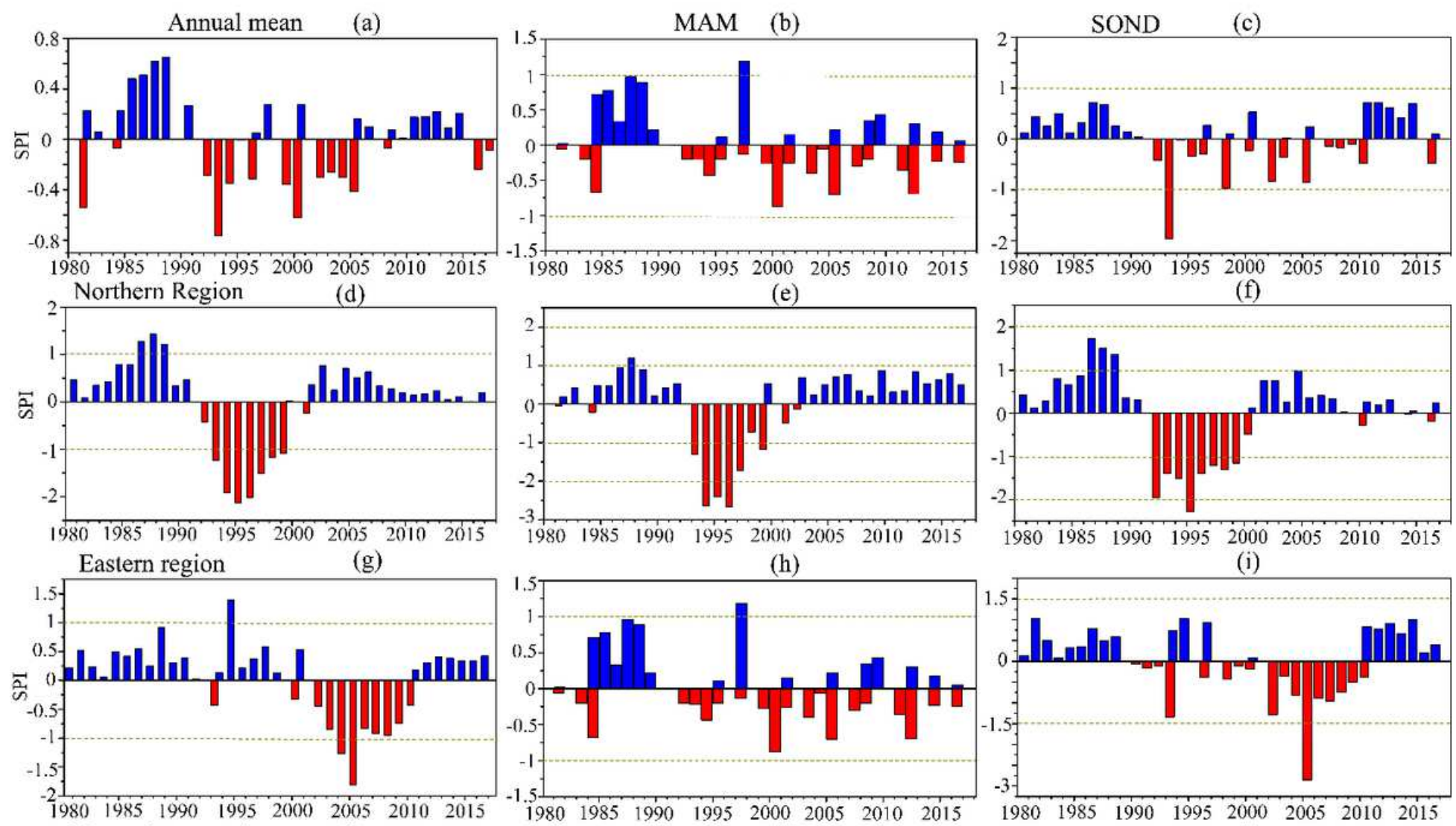

(i)
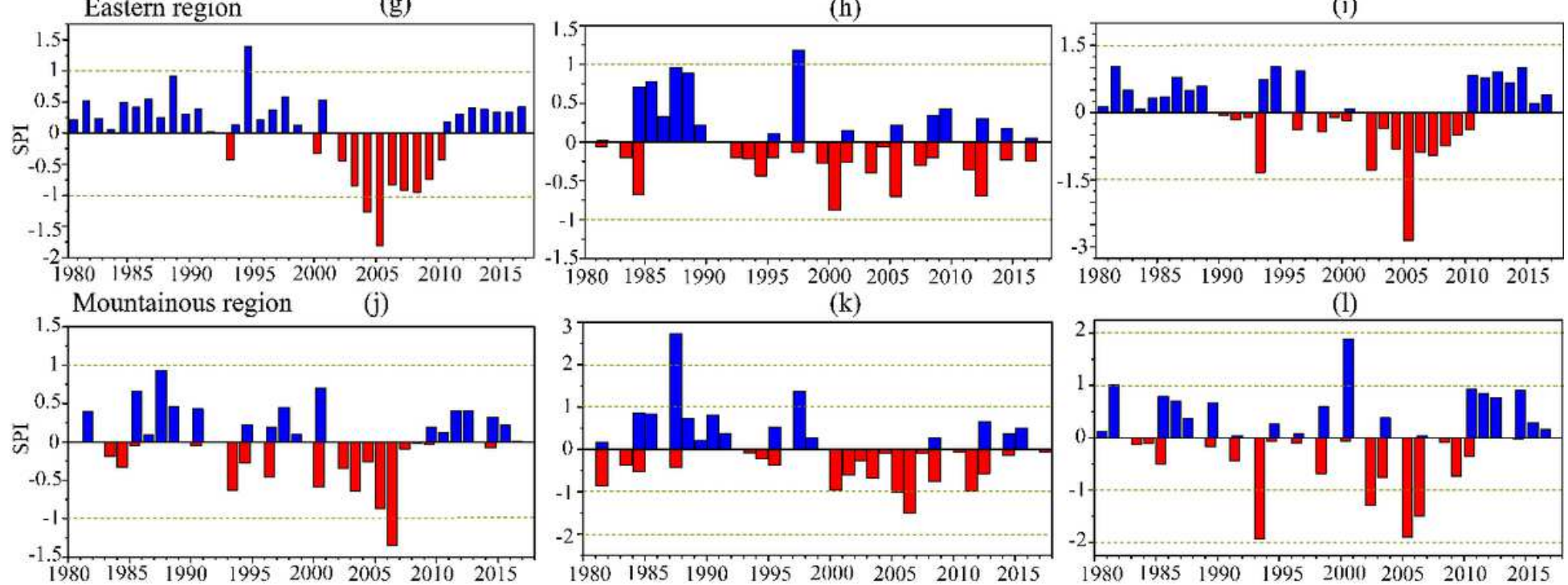

Figure 4

Comparison between annual and seasonal SPI-3 time series over the North, East and mountainous regions 


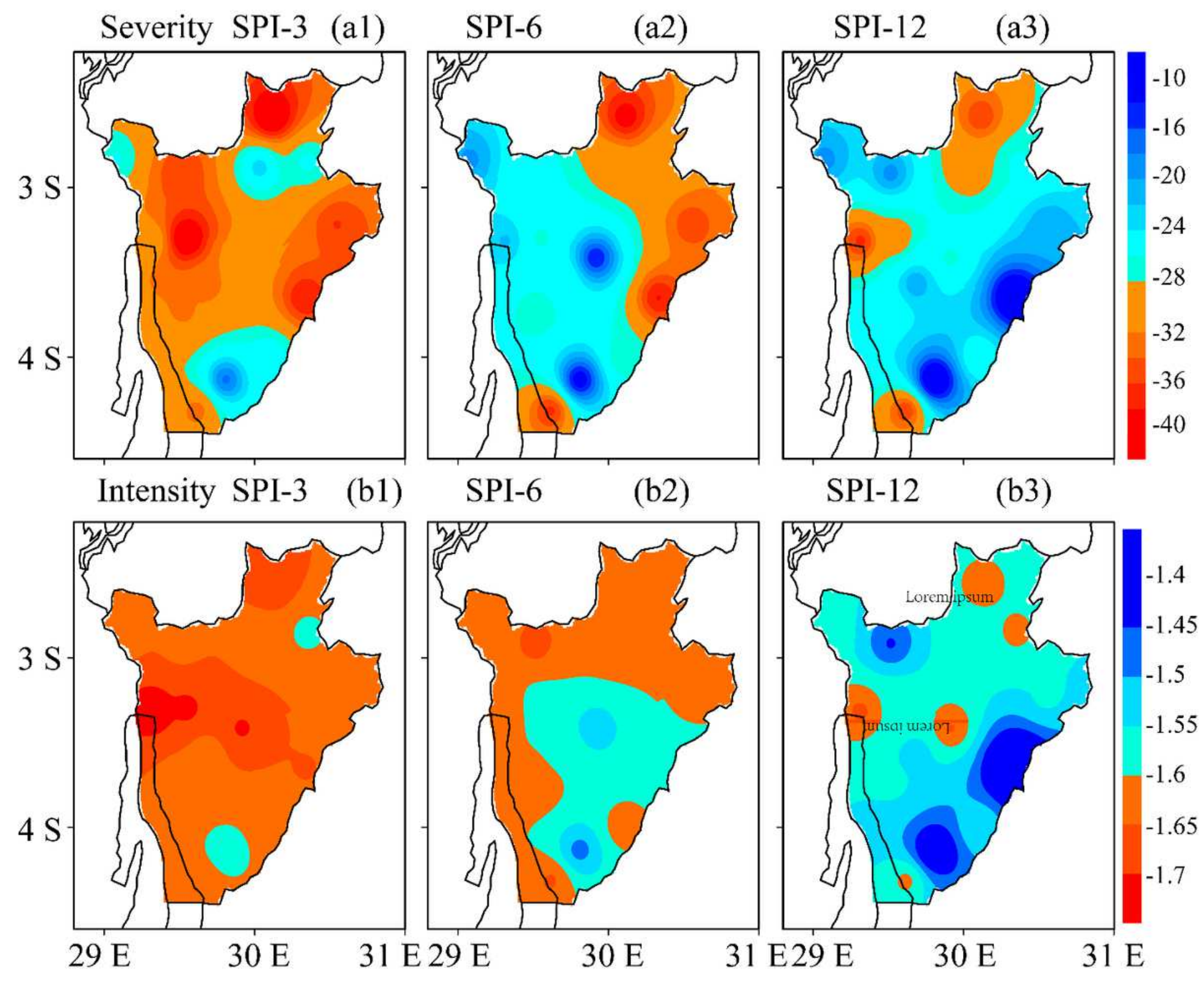

Figure 5

Spatial patterns of drought severity and intensity over 1981-2017 period using SPI-3, SPI-6 and SPI-12 values 

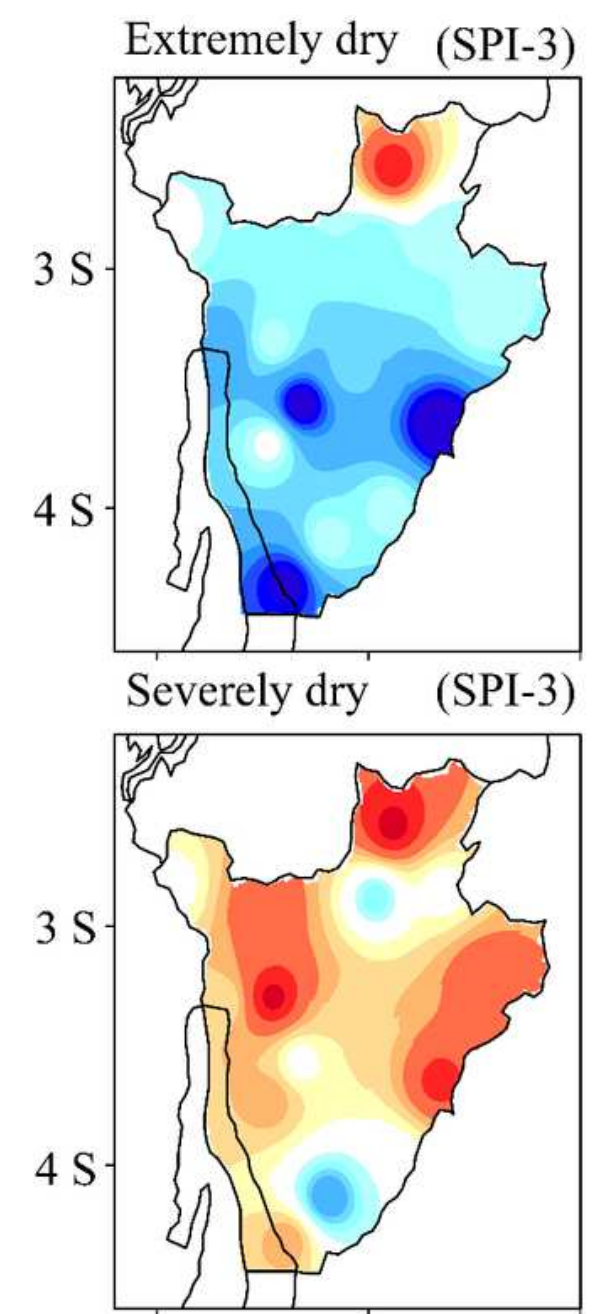

Moderately dry (SPI-3)
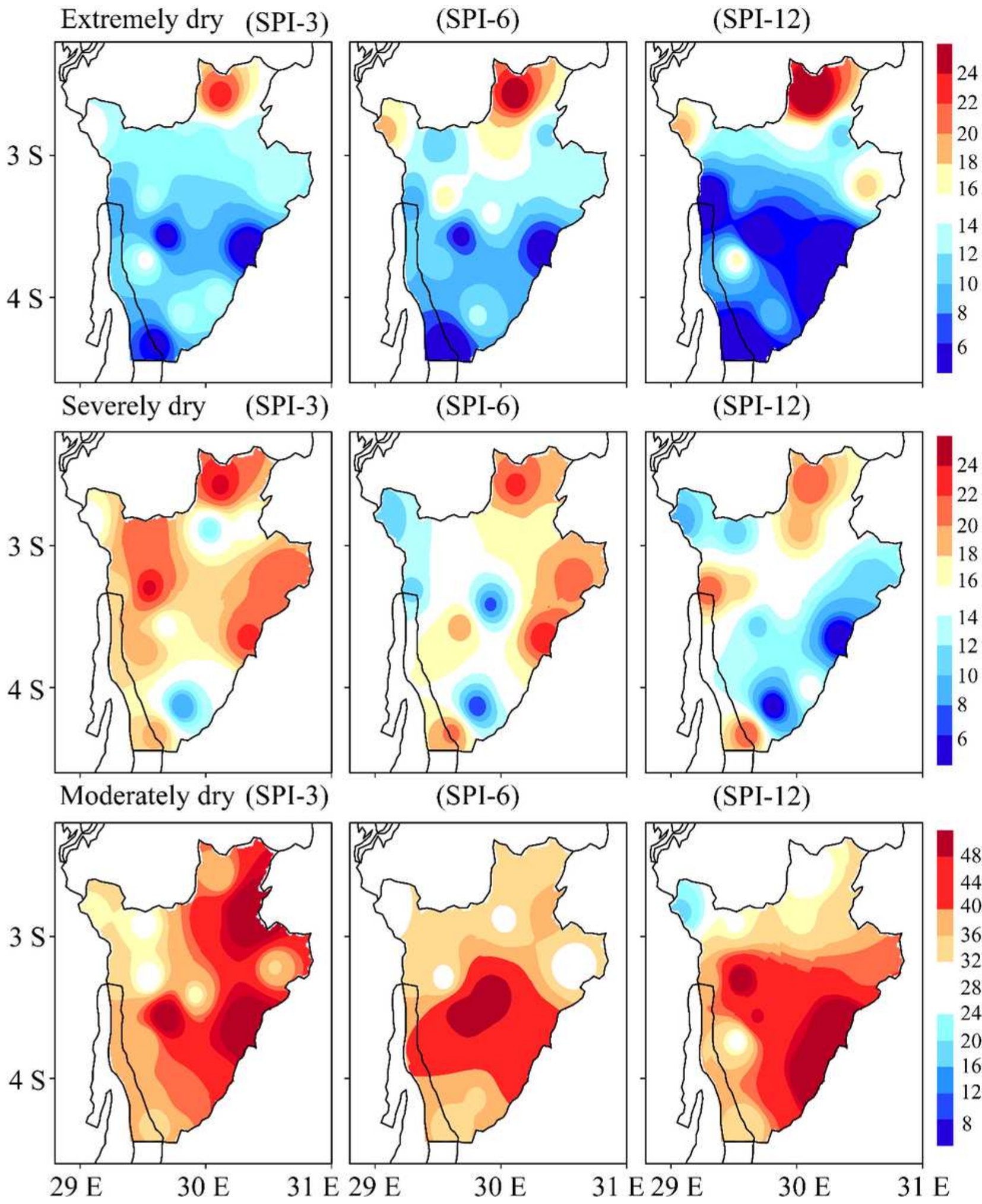

Figure 6

Spatial patterns of drought duration by the number of months based on 3,6 and 12-month time scales for extremely dry, severely dry and moderately dry for the period 1981-2017 averaged over Burundi 


\section{Mann Kendall trends}

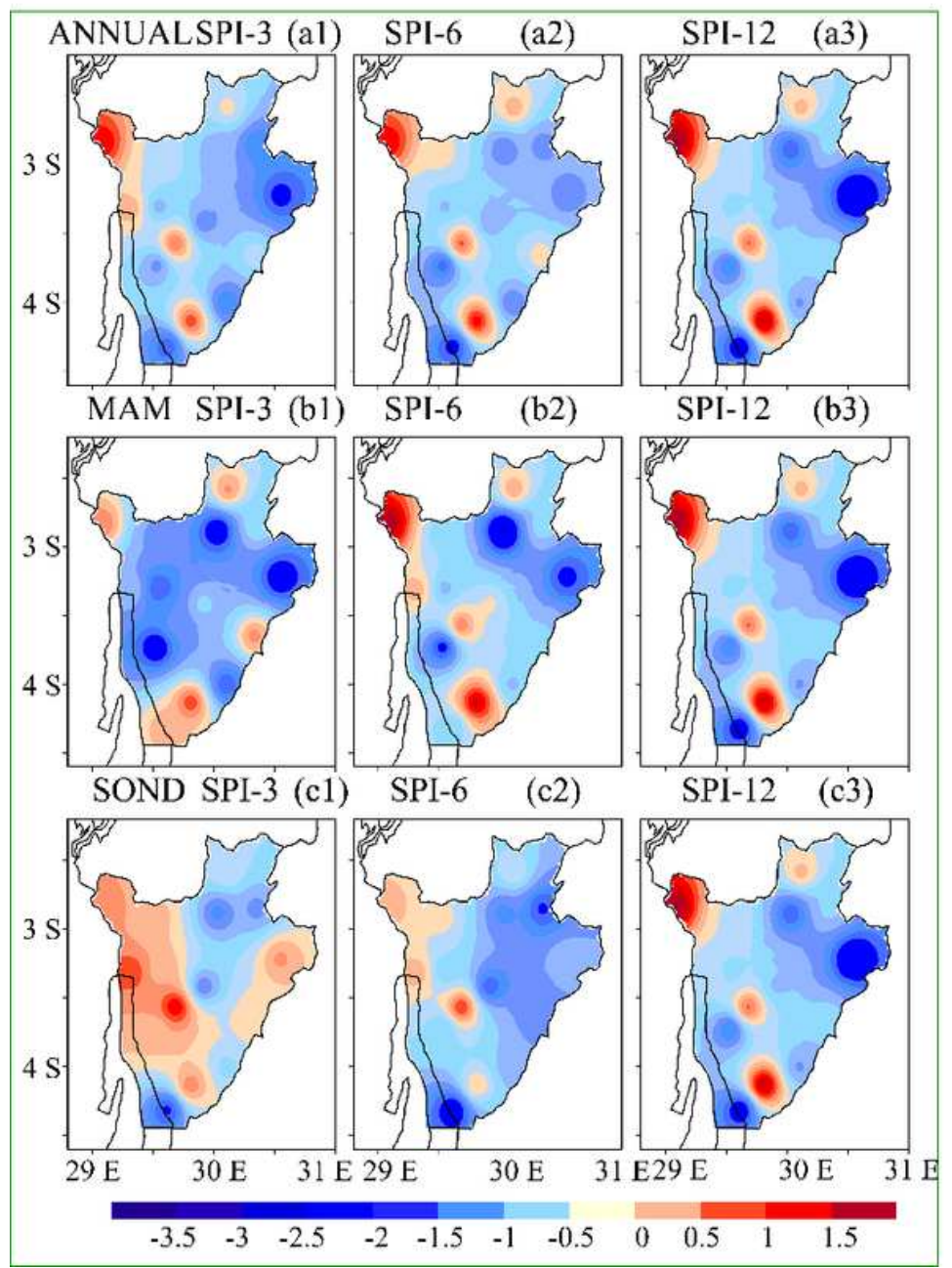

Modified Mann Kendall trends
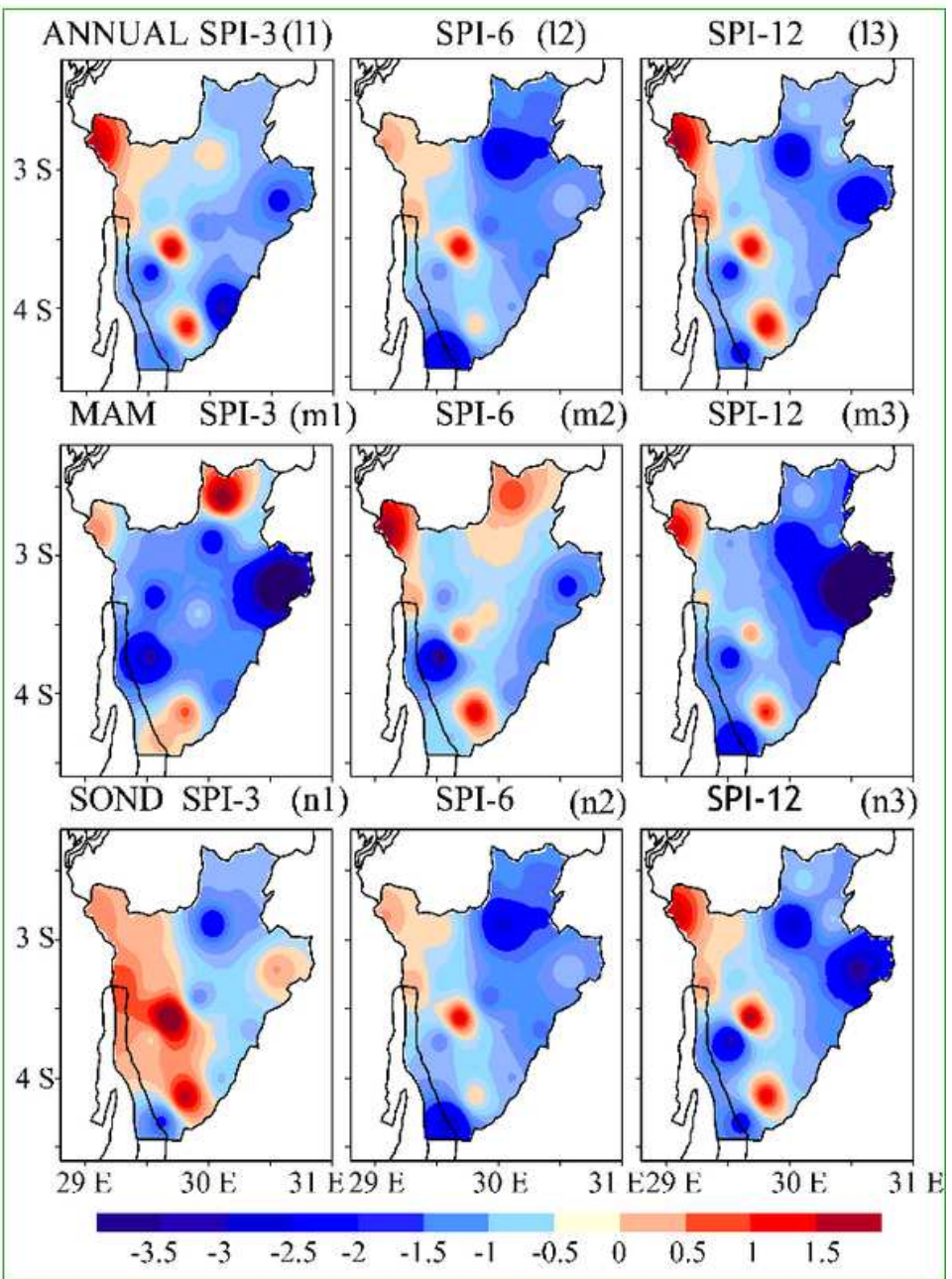

Figure 7

Comparison of spatial distribution of Mann Kendall and modified Mann Kendall trends in annual and seasonal SPI values generated with 3, 6 and 12-month timescales averaged on the period 1981-2017 over Burundi 

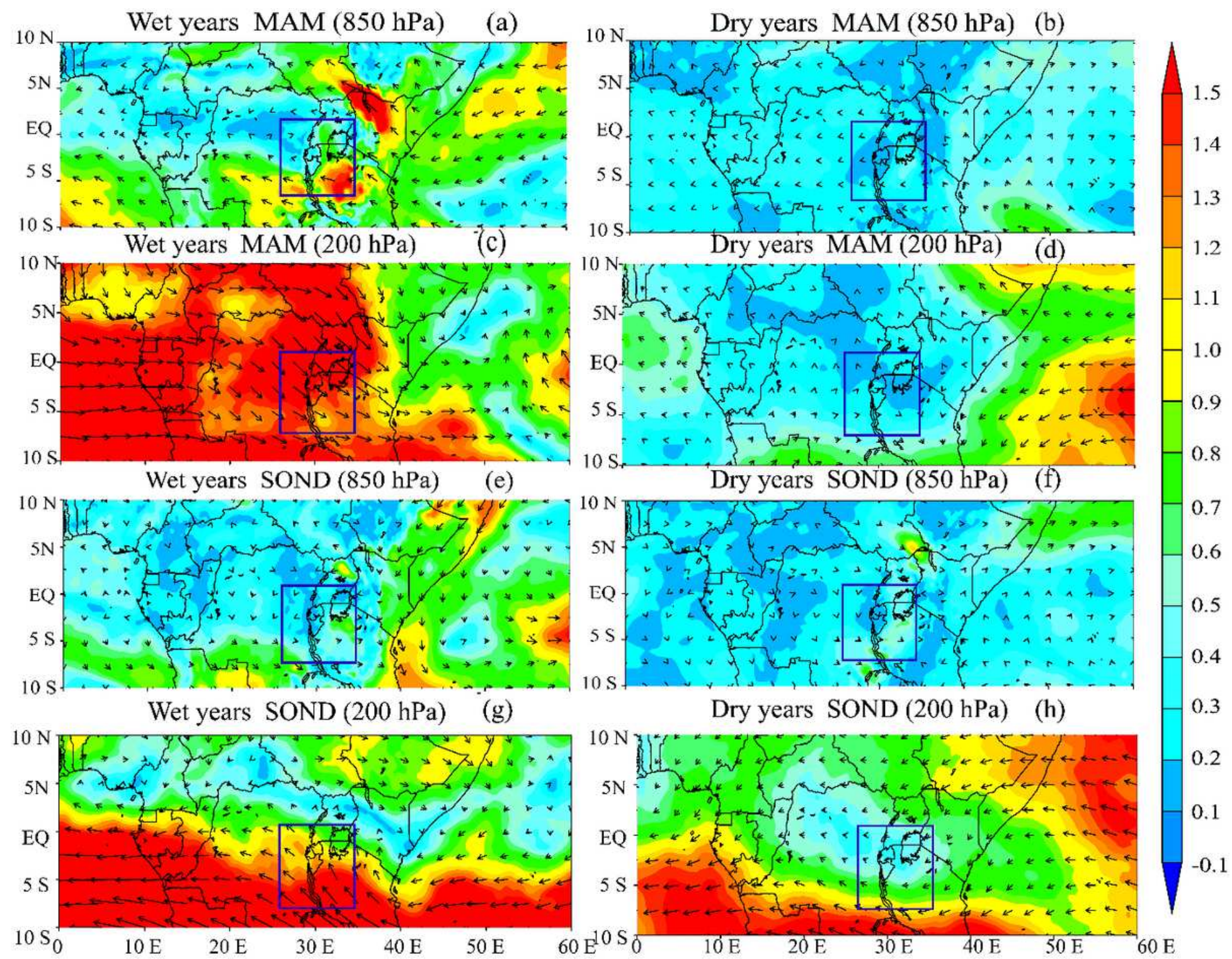

\section{Figure 8}

Composites of zonal and meridional winds anomalies (vector in ms-1) during wet and dry years overaged over long rains and short rains season. The blue box shows the study domain. 
MAM dry years at $850 \mathrm{hPa}$

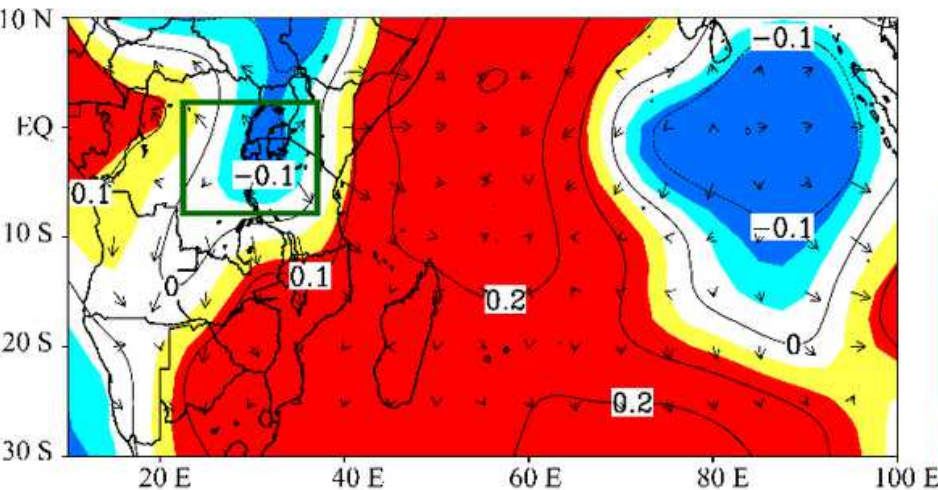

SOND dry years at $850 \mathrm{hPa}$ (a)

(c)
MAM dry years at $200 \mathrm{hPa}$

(b)

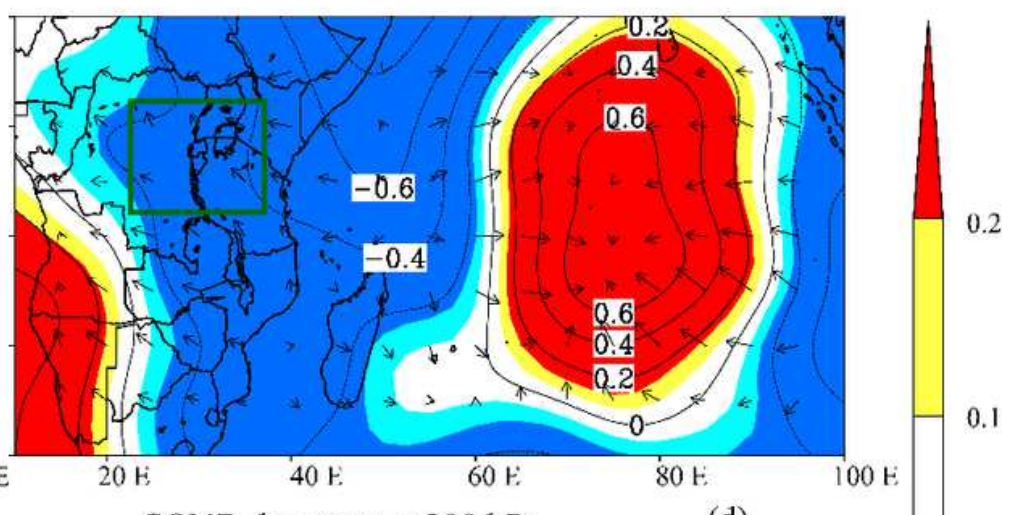

(d)

SOND dry years at $200 \mathrm{hPa}$
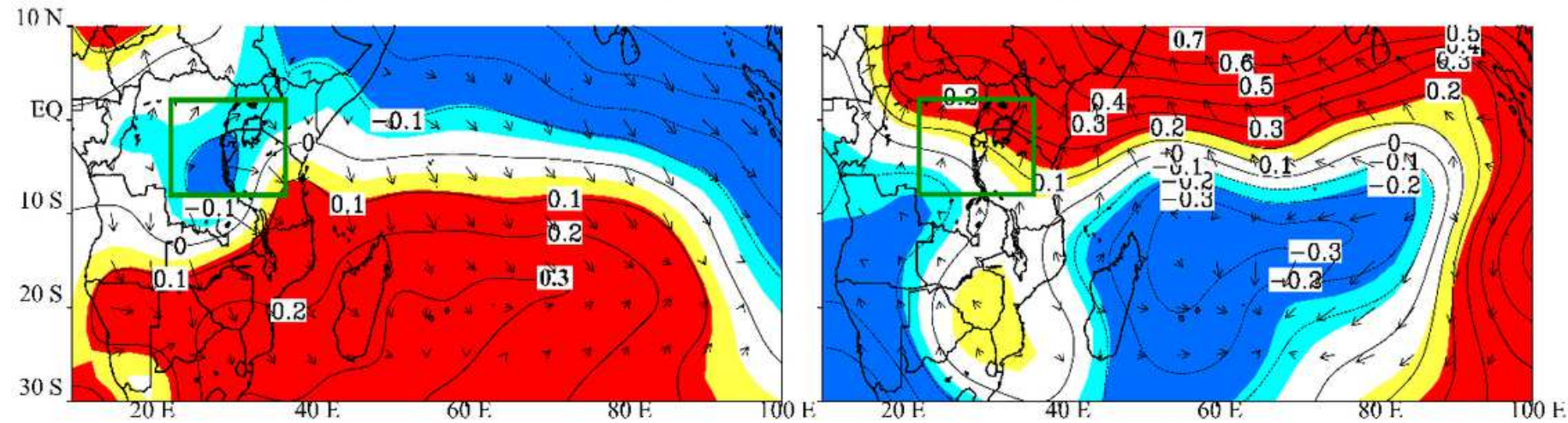

\section{Figure 9}

Composite of velocity potential (colored with contours) and divergence winds (vectors in ms- 1 ) anomalies during dry years at 850 and $200 \mathrm{hPa}$. The green box shows the study domain.

(a)

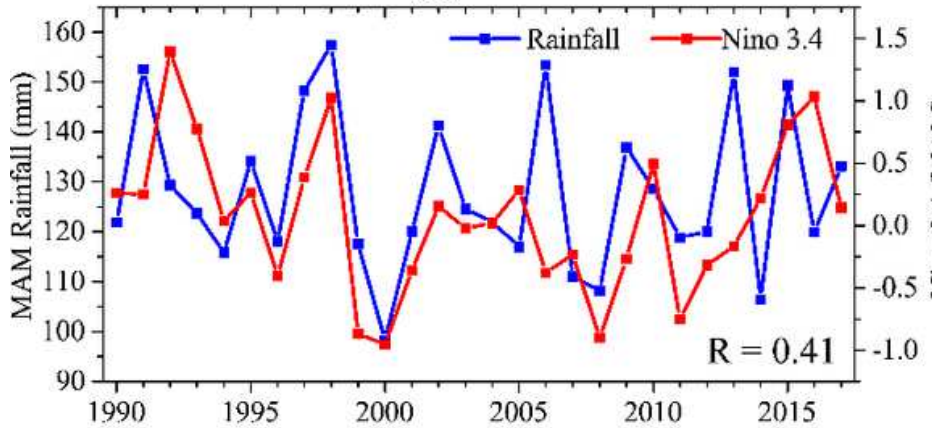

(c)

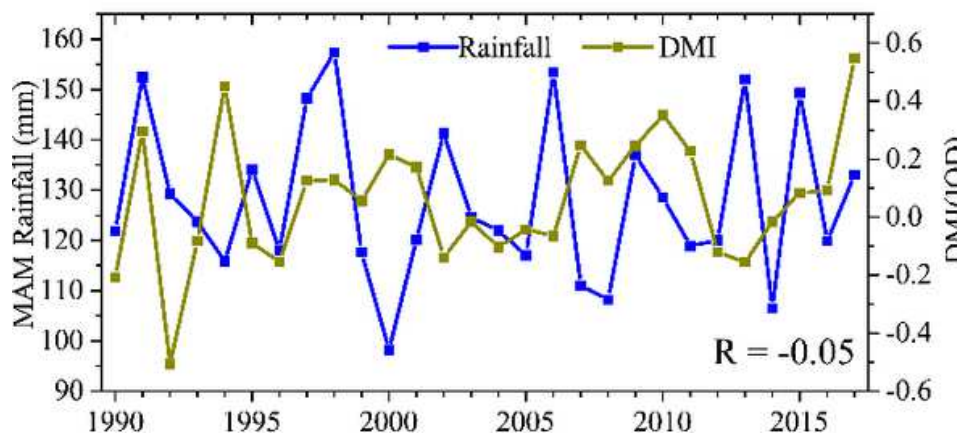

Figure 10 (b)

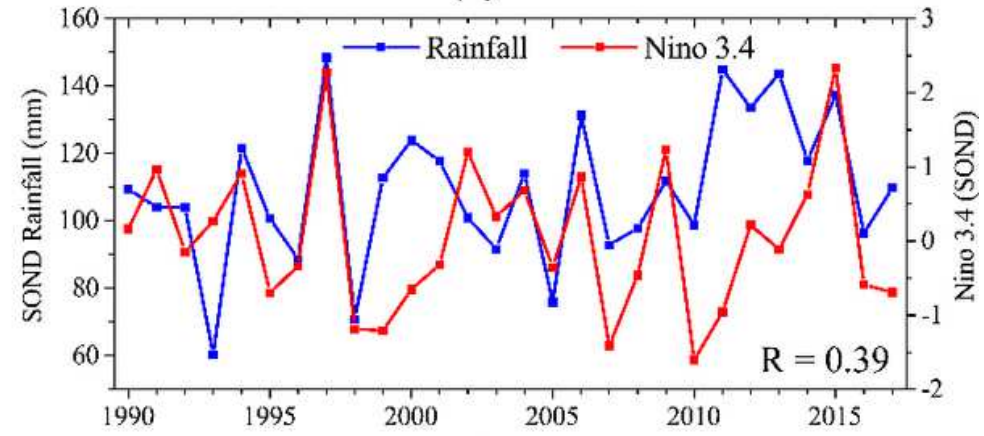

(d)

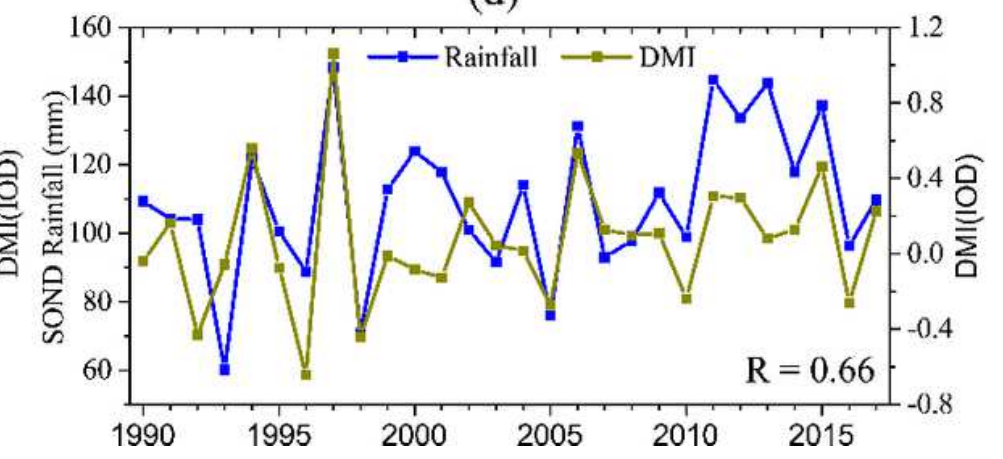


Correlation between MAM rainfall and Nino Index (a), SOND rainfall and Nino Index (b), MAM rainfall and DMI Index (c), SOND rainfall and DMI Index (d) 